\title{
A low-boom and low-drag design method for supersonic aircraft and its applications on airfoils
}

\author{
Liu-qing Ye, Zheng-yin Ye ${ }^{*}$, Kun Ye, Jie Wu and Sheng-jie Miao
}

\author{
* Correspondence: yezy@nwpu.edu. \\ School of Aeronautics, \\ Northwestern Polytechnical \\ University, Xi'an 710072, People's \\ Republic of China
}

\begin{abstract}
Sonic boom reduction has been an urgent need for the development of future supersonic transport, because of the heavy damage of noise pollution. This paper provides a novel concept for supersonic aircraft to reduce the sonic boom and drag coefficient, wherein a suction slot near the leading edge and an injection slot near the trailing edge on the airfoil suction surface are opened. To make sure of a zero net mass flux flow control, the mass flow sucked in near the leading edge is equal to the mass flow injected near the trailing edge. The diamond and NACA0008 airfoils are adopted as the baseline airfoil to verify the capability of the proposed design method. The effects of the suction and injection location, the suction and injection slot size, the mass flow rate and the attack angle on the ground boom signature and drag coefficient are studied in detail. The results show that the optimized airfoils with the suction and injection have benefits in both sonic boom reduction and wave drag reduction. And the reduction of the sonic boom intensity is more sensitive to the injection near the trailing edge than the suction near the leading edge. From the viewpoint of aerodynamics, opening the suction and injection slots will have no adverse effect on the aerodynamic performances of the supersonic aircraft and even increase the lift-drag ratio under some circumstances. For energy saving, the suction and injection slots can be selectively opened, which are opened when the supersonic aircraft flies over the city but are closed when the aircraft flies over the sea.
\end{abstract}

Keywords: Supersonic flow, Sonic boom, Supersonic aircraft, Optimization, Wave drag, Low-boom low-drag design

\section{Introduction}

Since the 21st century, a revived interest in civil supersonic flight has rekindled sonic boom research $[1,2]$. However, the mitigation of sonic booms, which can cause serious environmental problems for supersonic transport (SST), remains one of the biggest technical challenges for supersonic flight [3-6]. In 1947, the experimental Bell X-1 aircraft crossed the sound barrier and then supersonic flight became possible. Sonic boom is an acoustic phenomenon, which is inevitable in aircraft's supersonic flight. Since the first generation of supersonic aircraft entered service, such as Concorde and

(c) The Author(s). 2021 Open Access This article is licensed under a Creative Commons Attribution 4.0 International License, which permits use, sharing, adaptation, distribution and reproduction in any medium or format, as long as you give appropriate credit to the original author(s) and the source, provide a link to the Creative Commons licence, and indicate if changes were made. The images or other third party material in this article are included in the article's Creative Commons licence, unless indicated otherwise in a credit line to the material. If material is not included in the article's Creative Commons licence and your intended use is not permitted by statutory regulation or exceeds the permitted use, you will need to obtain permission directly from the copyright holder. To view a copy of this licence, visit http://creativecommons.org/licenses/by/4.0/. 
Tupolev TU-144, scientists and engineers from around the world have made extensive efforts in sonic boom research and have completed the standard sonic boom theory [7]. There are many excellent reviews [7-11] that present the generation, the prediction methods and the mitigation strategies of sonic boom. Owing to the fact that the noise created by a sonic boom can not satisfy regulations in most of the countries, these supersonic aircrafts are not allowed to fly over land and then even withdrew from the historical stage. However, it cannot be ignored that there is enormous potential business value for supersonic transport [12]. Therefore, reducing or even eliminating the sonic boom has been a hot issue both in engineering and academic domains.

In order to design a low-boom supersonic aircraft, two main technologies are used to reduce sonic booms: (1) aerodynamic minimization and (2) exotic configurations. The first technology $[13,14]$ is a traditional method mostly discussed in early studies, which mainly adopts aerodynamic means to minimize the sonic boom signals. Seebass [9] reviewed some of these methods, such as, reducing the engine streamtube area, decreasing annoying signatures of the aircraft, increasing lift/drag ratio, decreasing the structural weight, reducing the consumption of fuel and so on. In the last two decades, engineers and scientists have paid more attention to the second technology. Jones [15] and Carlson [16] are the first to reduce the sonic boom by aircraft shaping. They defined an equivalent-body shape, which can produce N-wave signature with a "lowerbound" overpressure and impulse. Carlson [17] further investigated the influence of configuration arrangement on the features of sonic boom. George and Seebass [18, 19] developed a relatively complete theory in which the area distribution is determined to minimize the head and tail shock, and it laid the theoretical foundation for the sonic boom minimization method. However, the nose shape determined by the area distribution is so blunt that the drag is significantly increased. And this method sacrifices the front fuselage size, and then results in the reduction in fuselage space utilization. For reducing the drag resulting from the blunt nose shape, Darden [20] modified and controlled the bluntness of the area distribution near the nose and further developed this minimization method. The inverse design approaches have been widely adopted for the low-boom supersonic configurations [21, 22]. This approach mainly designates a target near-field or far-field pressure signature and achieves it by shaping the aircraft. Based on the augmented Burgers equation and Proper Orthogonal Decomposition (POD) method, Zhang [23] developed an inverse design framework for supersonic low-boom configuration. Recently, some innovative concepts have been proposed to reduce the sonic boom and wave drag of supersonic aircraft. Placing a swept forward keel normal to the Mach plane to increase the apparent length of the aircraft, Marconi [24] has proved that this method is effective to alleviate the sonic boom. Howe [25] proposed a Quiet Spike concept to mitigate the sonic boom. An extendable and retractable spike is mounted on the nose to produce a series of weak shock waves, and then the sonic boom can be reduced. However, the additional spike will significantly increase the weight of aircraft, and it must be equipped with adequate stiffness to avoid the aeroelastic instability [26]. Ban [27] adopted a supersonic biplane concept and a supersonic twin-body concept to reduce the sonic boom and wave drag of supersonic transport. Establishing the multidisciplinary methodologies for supersonic transport, Sun et al. $[28,29]$ evaluated the sonic boom characteristics and aerodynamics of six business- 
class configurations. And they finally found out the low-boom and low-drag design solutions.

This paper proposes a novel concept for supersonic aircraft to reduce the sonic boom and drag coefficient, wherein a suction slot near the leading edge and an injection slot near the trailing edge on the airfoil suction surface are opened. Compared with the above low-boom methods, the novel method proposed in this paper not only avoids the weight penalty and substantial increment of drag but also the sacrifice of fuselage space. On the other hand, this method has the advantages of simple operation and easy control. For energy saving, the suction and injection slots are opened when the supersonic aircraft flies over the city, and they are closed when the aircraft flies over the sea. In order to verify the capability of the proposed design method, the diamond and NACA0008 airfoils are adopted as the baseline airfoil. This paper is organized as follows: Section 2 introduces the specific strategy for reducing the sonic-boom and drag coefficient. In Section 3, firstly the optimal locations for suction and injection slots are found, and then the suction slot and the injection slot are placed at the corresponding optimal locations, and the effects of suction and injection slot size, the mass flow rate and the attack angle on the ground boom signature and drag coefficient are numerically studied in detail. The concluding remarks are provided in Section 4.

\section{The strategy for reducing the sonic-boom and drag coefficient}

\subsection{Sonic-boom formation and propagation}

A sonic boom results from the natural nonlinear evolution of shock waves and nearfield pressure disturbances [30]. The near-field pressure disturbances propagate away from the supersonic aircraft, and several different shock waves produced by the aircraft features coalesce into the classic N-wave in the far field, shown in Fig. 1. The classic Nwave, which denotes the shape of pressure signatures, is formed by a leading and

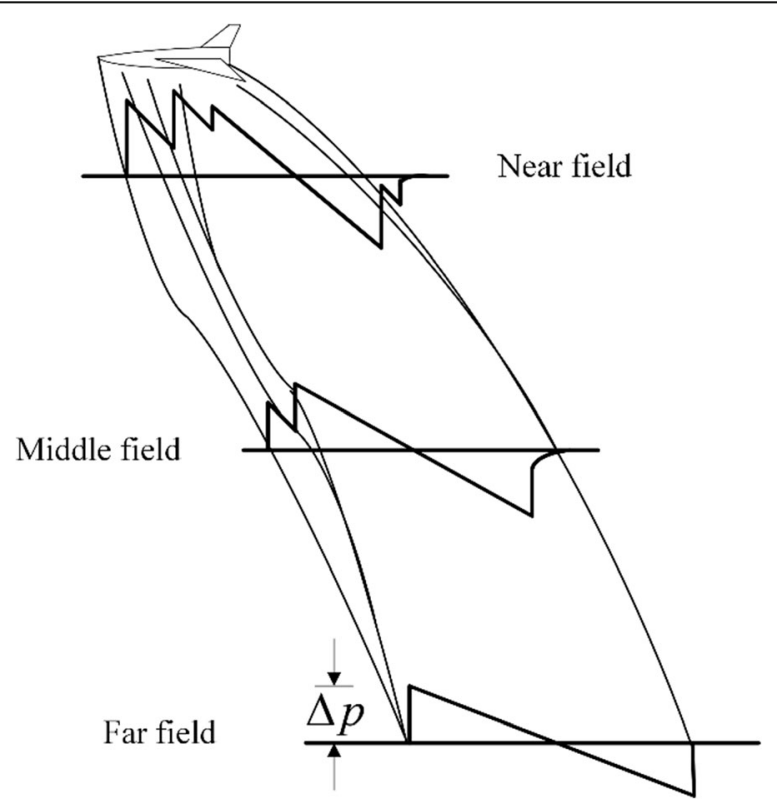

Fig. 1 Schematic of sonic boom propagation (not to scale) 
trailing shock. An almost linear pressure expansion separates the leading shock from the trailing shock. When a part of the effective acoustic energy reaches the ground, the human ear perceives sound and it is called a sonic boom. Only a single bang can be perceived by the human ear when the aircraft is small. This results from the fact that the leading shock is very close to the trailing shock. For a relatively long or large aircraft, a boom-boom will be perceived by the human ear. There is an expansion between the leading shock and the trailing shock, which can not be perceived by the human ear because of its sufficiently low frequency.

\subsection{Low-boom and low-drag design method}

This paper provides an effective method for supersonic aircraft to reduce the sonic boom and drag coefficient. Shown in Fig. 2, the low-boom and low-drag design method for supersonic aircraft is to open a suction slot near the leading edge and an injection slot near the trailing edge on the airfoil suction surface. The aerodynamical principle of the method is that the suction near the leading edge can produce a series of expansion waves to weaken the front sharp pressure rise, which is produced by the leading shock. And the injection near the trailing edge can produce shock waves, which will weaken the rear sharp pressure rise resulting from the trailing shock. Thus, the low sonicboom can be obtained by reducing the maximum overpressure and maximum underpressure.

To verify and highlight the capabilities of the proposed design method, the diamond and NACA0008 airfoils, which are common supersonic airfoils, are adopted as the baseline airfoil. The geometries of the diamond and NACA0008 airfoil baseline and the geometries of the optimized diamond and NACA0008 airfoils are presented in Fig. 2(a) and (b), respectively. Thereinto, $\mathrm{c}$ is the chord length. The angles of flow passing the suction slot and the injection slot are perpendicular to the suction surface and injection surface, respectively. For minimizing the power consumption, the mass flow sucked in near the leading edge is the same as the mass flow injected near the trailing edge to make sure it is a zero net mass flux flow control. The flow control is powered by a pump.
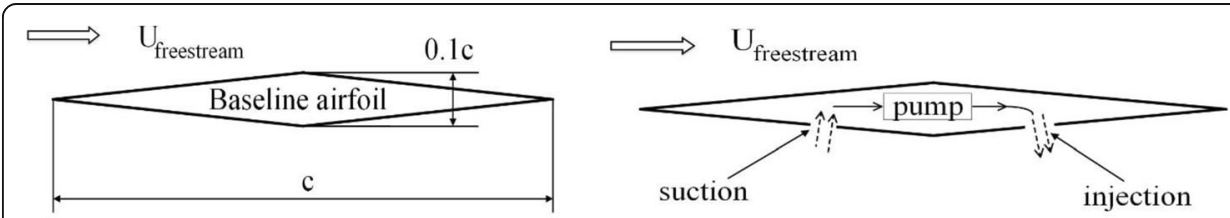

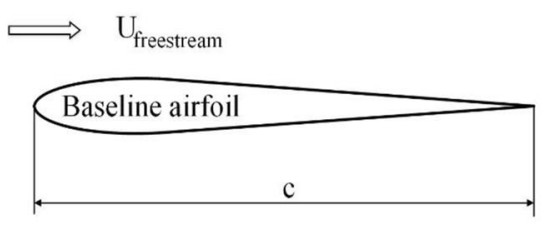

(a)

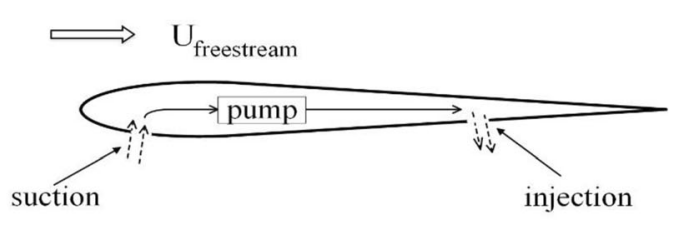

(b)

Fig. 2 Supersonic airfoils. a Baseline diamond and NACA0008 airfoils; b optimized diamond and NACA0008 airfoils with both suction and injection 


\subsection{Sonic-boom prediction}

In order to verify the capabilities of the method in reducing the sonic boom and drag coefficient, it is significant to accurately predict the ground sonic boom signatures. At present, the international mainstream strategy of a sonic-boom prediction first proposed by Cheung [31] and Siclari [32], which is also adopted in this paper, consists of two main steps. First, using the wind tunnel experiment or a computational fluid dynamics (CFD) calculation, the near-field pressure signatures can be obtained. Then, the off-body-pressure distribution in the near-field region is propagated to the ground to achieve the ground sonic boom signature by utilizing quasi-linear theory derived from Whitham [33] and methods originating from the nonlinear Burger's [34] and Tricomi's equation [35, 36].

The mesh tool, ICEM, is utilized to provide the structured mesh. For capturing the shock features more accurately, the grid surface is parallel to the shock surface and the grid near the shock surface is densified. By solving 2-D Euler equation, the commercial CFD software, Fluent, is used to obtain the near-field pressure distribution by calculating the flow field. Xu [37] conducted CFD calculations and analyses on the standard model proposed by the 1st AIAA Sonic Boom Prediction Workshop (SBPW-1), and then pointed out that the viscous effect can be ignored in the analysis of sonic boom with a simple shape, in other words, the model error of the Euler equation can be ignored.

Based on the modified supersonic linearization theory developed by Whitham [33], the linear far-field propagation methodology of Thomas [38] and geometrical acoustics, the authors' Division has developed an in-house package FL-BOOM [2] to estimate the effects of the far-field propagation. As a comprehensive sonic boom signal propagation and analysis tool, it has already been proved that FL-BOOM can provide an acceptable result for the prediction of sonic-boom signatures in Ref [2], and it is used to conduct the far-field calculation in this paper.

The linearized theory of sonic boom prediction was developed by Whitham from the linearized theory for the supersonic slender body of revolution in 1952. Whitham thought that the assumption that the characteristic lines are parallel to each other is not reasonable in the calculation of a sonic boom. He modified the characteristic line equation, proposed the linearized theory of sonic boom and also gave the description for characteristic lines with high precision. According to the linearized theory for the supersonic slender body of revolution, the small perturbation velocities of revolution bodies are

$$
\left\{\begin{array}{l}
\frac{\hat{u}}{V_{\infty}}=\frac{\partial \phi}{\partial x}=-\frac{1}{2 \pi} \int_{0}^{x-B r} \frac{S^{\prime \prime}(\xi) d \xi}{\sqrt{(x-\xi)^{2}-B^{2} r^{2}}} \\
\frac{\hat{v}}{V_{\infty}}=\frac{\partial \phi}{\partial r}=-\frac{1}{2 \pi r} \int_{0}^{x-B r} \frac{S^{\prime \prime}(\xi)(x-\xi) d \xi}{\sqrt{(x-\xi)^{2}-B^{2} r^{2}}}
\end{array}\right.
$$

where $\hat{u}$ and $\hat{v}$ are small perturbation velocities, $V_{\infty}$ is flow velocity at infinity, $\phi$ is velocity potential, $x$ and $r$ are cylindrical coordinates, $B=\sqrt{M a^{2}-1}, M a$ is Mach number, $\xi$ is integration variable, $S(\xi)$ is sectional area and $S^{\prime \prime}(\xi)$ is the second derivative of the cross section. 
The characteristic line equation $x-B r=$ const is changed to $x-B r=y(x, r)$. It means that the relationship between $x$ and $r$ is not linear, and this relationship is related to space coordinates $(x, r)$. Thus, the eq. (1) can be expressed as

$$
\left\{\begin{array}{l}
\frac{\hat{u}}{V_{\infty}}=-\frac{1}{2 \pi} \int_{0}^{y} \frac{S^{\prime \prime}(\xi) d \xi}{\sqrt{(y-\xi)(y-\xi+2 B r)}} \\
\frac{\hat{v}}{V_{\infty}}=-\frac{1}{2 \pi r} \int_{0}^{y} \frac{S^{\prime \prime}(\xi)(y+B r-\xi) d \xi}{\sqrt{(y-\xi)(y-\xi+2 B r)}}
\end{array}\right.
$$

Because the characteristic line of disturbance is initiated from the object surface, $y=$ $x-B r=x-B R$ when $r=R$, and $y$ is of the same order of magnitude as the axial length of the body of revolution. For $r \gg R$, it obtains $y / B r \ll 1$, also considering $\xi=o(y)$, then we can obtain

$$
\begin{aligned}
& \frac{\hat{u}}{V_{\infty}}=-\frac{1}{2 \pi} \int_{0}^{y} \frac{1}{\sqrt{2 B r}} \frac{S^{\prime \prime}(\xi) d \xi}{\sqrt{y-\xi}} \\
& =-\frac{1}{\sqrt{2 B r}} F(y) \\
& F(y)=\frac{1}{2 \pi} \int_{0}^{y} \frac{S^{\prime \prime}(\xi) d \xi}{\sqrt{(y-\xi)}}
\end{aligned}
$$

The above eq. (4) gives the expression of the function $F(y)$, which is very important in the sonic boom prediction theory.

According to the Bernoulli's equation, it obtains

$$
\begin{aligned}
& \Delta p=\frac{1}{2} \rho_{0}\left(V_{\infty}^{2}-V^{2}\right) \\
& \Delta p=\frac{1}{2} \rho_{0}\left(V_{\infty}^{2}-\left(V_{\infty}+\hat{u}\right)^{2}-\hat{v}^{2}\right)
\end{aligned}
$$

Considering $\hat{u} \ll V_{\infty}, \hat{v} \ll V_{\infty}$, the eq. (5) can be expressed as follows

$$
\Delta p=-\rho_{0} V_{\infty} \hat{u}
$$

Substituting eq. (3) into eq. (6), it obtains

$$
\frac{\Delta p}{p_{0}}=\frac{r M a^{2}}{\sqrt{2 B r}} F(y)
$$

where $\Delta p / p_{0}$ is the overpressure and $\Delta p=p-p_{0} \cdot p$ is the local pressure at the observation point and $p_{0}$ is the environmental pressure.

Here the expression of characteristic line is given as follows

$$
\left\{\begin{array}{l}
x=B r-k F(y) \sqrt{r}+y \\
y=x_{0}-B r_{0} \\
k=2^{-1 / 2}(\gamma+1) M a^{4} B^{-3 / 2}
\end{array}\right.
$$

where $\gamma$ is the specific ratio, and $x_{0}, r_{0}$ are the initial position coordinates.

When the waveform shape on the ground is obtained, according to the references $[28,39]$, we can select the maximum overpressure and maximum underpressure as the main indices of sonic boom intensity. Here, $\Delta p_{-} o$ represents the maximum overpressure and $\Delta p_{-} u$ indicates the maximum underpressure. 


\section{Results and discussion}

The freestream Mach number adopted in this Section is $\mathrm{Ma}=1.7$ for the numerical computation. The chord length of the airfoil is $1 \mathrm{~m}$. The boundary condition of the suction is set as the pressure outlet condition, and the boundary condition of the injection is simulated with the velocity inlet condition. By adjusting the velocity value of the jet at the velocity inlet condition, the mass flow passing the injection slot is controlled to be the same as that sucked in the suction slot. For the far-field propagation, the ground signatures for the airfoil baseline and the designed airfoil are propagated with FLBOOM from the near-field pressure distributions calculated with CFD at two body lengths away from the aircraft, i.e. $\mathrm{H} / \mathrm{L}=2$. The real aircraft is assumed at an altitude of $16764 \mathrm{~m}$ and in a no-wind U.S. Standard Atmosphere [2].

In this Section, we compare the ground sonic boom signatures and drag coefficients of the designed airfoils with that of the airfoil baselines to verify the capabilities of the proposed design method, which can significantly reduce the sonic boom and drag coefficient of the supersonic aircraft. During the calculation of aerodynamic coefficients, two factors (i.e. (1) momentum fluxes of the suction and injection slots (2) pressures at the suction and injection slots) have been considered. Based on dimensional analysis, momentum flux means the force per unit area. According to the momentum theory, the acting force of this part on the suction and injection slots can be obtained. For the pressures at the suction and injection slots, they are obtained when the flow field is solved. In Section 3.1, the mesh convergence analysis is conducted. In Section 3.2, the sonic boom prediction model is verified. In Section 3.3, without opening the suction and injection slots simultaneously, here we only open a suction slot near the leading edge or an injection slot near the trailing edge at different locations. Then the effects of suction and injection location on the ground sonic boom signatures are studied, and the optimal location for the suction slot and the injection slot is found. In Section 3.4, 3.5 and 3.6, opening the suction and injection slots simultaneously and putting the suction slot and the injection slot at the optimal location found in Section 3.3, the effects of the suction and injection slot size, the mass flow rate and the attack angle on the ground boom signature and drag coefficient are numerically studied, respectively. The mass flow sucked in near the leading edge is equal to the mass flow injected near the trailing edge.

\subsection{Mesh convergence}

Three structured meshes, i.e. coarse, medium, and fine, were generated to conduct the mesh convergence analysis for the present test cases. The different grid refinement levels can be distinguished by different line types. The number of nodes of the grid at the next finer level is four times as much as that at the last level. The near-field pressure distributions at $\mathrm{H} / \mathrm{L}=2$ for optimized diamond airfoil with suction injection (Fig. 3(a)) and for optimized NACA0008 airfoil with suction injection (Fig. 3(b)) are calculated. The mass flow rate at the suction slot is the same as that at the injection slot.

In the case of optimized diamond airfoil, the numbers of the grid nodes are $190 \times$ 200, $290 \times 400$ and $390 \times 800$, respectively. The suction slot is located at $21.0 \%$ c from the leading edge, and the injection slot is located at $79.0 \% \mathrm{c}$ from the leading edge. The mass flow rate at the suction and injection slot is $1 \mathrm{~kg} / \mathrm{s}$, and the size of suction and 


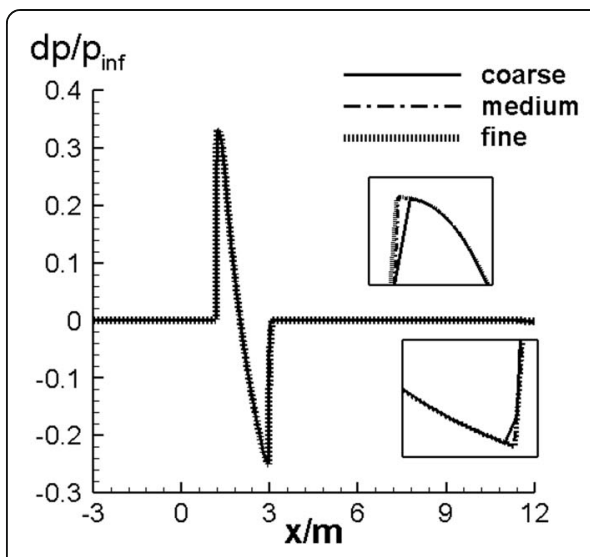

(a)

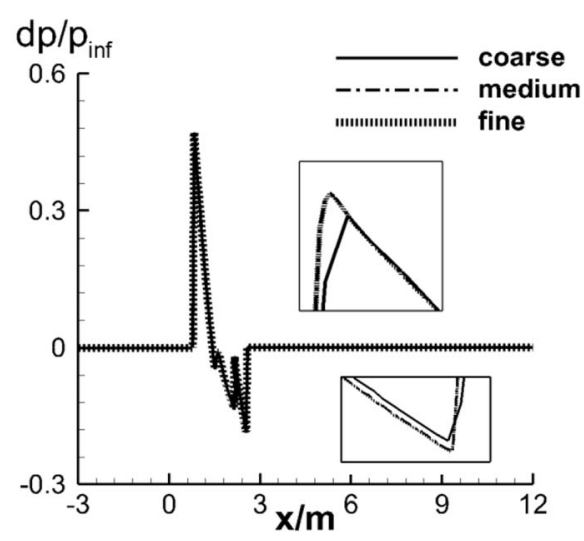

(b)

Fig. 3 Near-field pressure distributions at $H / L=2$. a for the optimized diamond airfoil with suction injection; b the optimized NACA0008 airfoil with suction injection

injection slot is $2 \%$ c. In the case of optimized NACA0008 airfoil, the numbers of grid nodes are $190 \times 206,380 \times 412$ and $760 \times 824$, respectively. The suction slot and the injection slot are located at $16.1 \% \mathrm{c}$ and $79.3 \% \mathrm{c}$ from the leading edge, respectively. The mass flow rate at the suction and injection slot is $1.9 \mathrm{~kg} / \mathrm{s}$, and the size of suction and injection slot is $2 \%$ c.

Figure 3 shows the mesh convergence analysis. The results show that for different grid refinement levels, the positions of the shocks and expansions are kept consistent. The partial enlarged details in Fig. 3 show that higher pressure magnitudes of shocks and expansions are obtained for the fine grids with less dissipation, which have shown in Refs $[2,4]$.

\subsection{The verification of the sonic boom prediction model}

Firstly, the prediction method of using CFD technology to obtain near-field sonic boom signatures should be verified. Table 1 shows aerodynamic coefficients of the diamond airfoil by using the theoretical method and the present CFD technology, respectively. $\alpha$ is the angle of attack. It can be seen that CFD results are very close to the theoretical results. Thus, the present CFD simulation technology can be used for calculating the near-field pressure distributions.

In order to test our far-field calculation system FL-BOOM, Lockheed Martin 1021 configuration (LM1021) is selected as the test model. The LM1021 test case provided by Lockheed Martin, as part of the NASA N +2 supersonic validation program, is a full

Table 1 Aerodynamic coefficients and the corresponding error of diamond airfoil by using different methods

\begin{tabular}{|c|c|c|c|c|c|c|}
\hline \multirow{2}{*}{$\begin{array}{l} \\
\rho^{\circ}\end{array}$} & \multicolumn{3}{|l|}{$\mathrm{Cd}$} & \multicolumn{3}{|l|}{$\mathrm{Cl}$} \\
\hline & $\begin{array}{l}\text { CFD } \\
\text { technology }\end{array}$ & Theoretical method & Error / \% & $\begin{array}{l}\text { CFD } \\
\text { technology }\end{array}$ & Theoretical method & Error / \% \\
\hline 0 & 0.02918 & 0.02910 & 0.27 & 0 & 0 & - \\
\hline 2 & 0.03297 & 0.03264 & 1.01 & 0.1035 & 0.1016 & 1.8 \\
\hline
\end{tabular}


complex configuration with three nacelles and a $\mathrm{V}$ tail mounted on a blade support. The detailed geometry of LM1021 configuration can be seen in Ref. [2]. The inviscid simulation results of near-field signatures for $h / L=1.42$ and off-track angle $\phi$ deg are propagated to the ground. The full-scale vehicles are assumed to be at an altitude of $16764 \mathrm{~m}$ and a Mach number of 1.6 in a no-wind U.S. Standard Atmosphere. Figure 4 shows the comparison of propagated ground signatures from FL-BOOM and from the submissions of the 1st AIAA Sonic Boom Prediction Workshop (SBPW-1). It can be seen in Fig. 4 that the far-field signature generated by FL-BOOM catches shocks correctly and gives a generally acceptable shape of the waveform.

\subsection{The effects of suction and injection location}

To achieve optimal results (i.e. the lowest sonic boom level) when the present method is used, the optimal locations for the suction slot and the injection slot should be found. Without opening the suction and injection slot simultaneously, here we only open a suction slot near the leading edge at different locations and study the effects of suction location on the maximum overpressure, then the optimal suction location can be found. Similarly, opening only an injection slot near the trailing edge at different locations, the effects of injection location on the maximum underpressure are studied and then the optimal injection location can be determined. $\mathrm{x}_{-} \mathrm{s}$ is the distance between the suction slot and the leading edge, and $x_{-} i$ denotes the distance between the injection slot and the leading edge. To compare the performance of optimized diamond airfoil and the diamond baseline airfoil, the maximum overpressure and the ground sonic

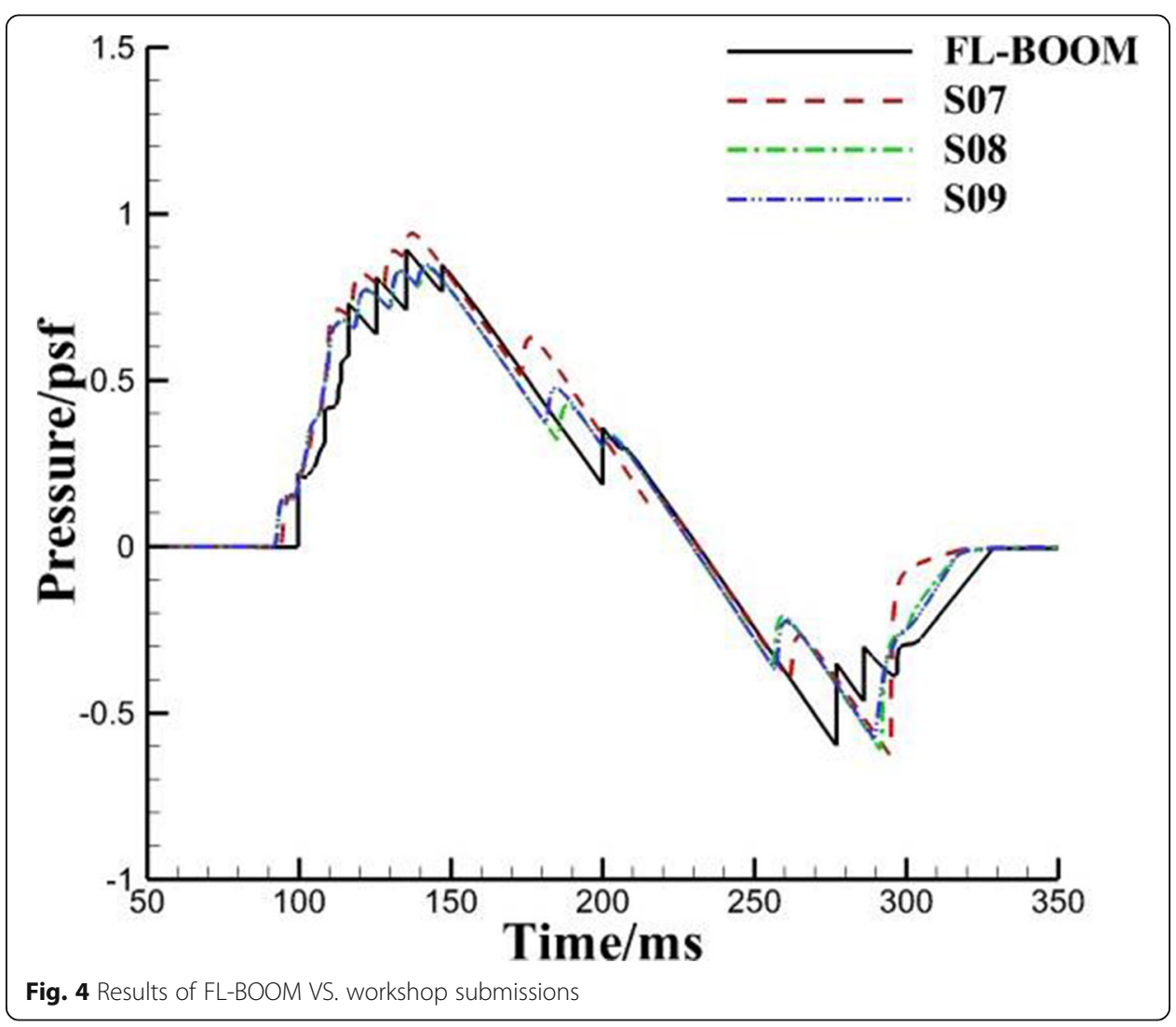


boom signature of the designed and baseline airfoil are shown in Figs. 5 and 6, respectively. For the diamond baseline airfoil, the maximum overpressure and maximum underpressure of the ground sonic boom signature are $0.727 \mathrm{psf}$ and-0.705psf, respectively.

Opening only a suction slot at different locations, the effects of the suction location on the maximum overpressure are presented in Fig. 5(a). The suction locations range from $0.04 \mathrm{~m}$ to $0.46 \mathrm{~m}$ (i.e. $\mathrm{x} \_\mathrm{s}$ ranges from $0.04 \mathrm{~m}$ to $0.46 \mathrm{~m}$ ), and the interval is 0.02 $\mathrm{m}$. Here the length of suction slot is $4 \%$ chord. The mass flow rate at the suction slot is about $-6.428 \mathrm{~kg} / \mathrm{s}$. It can be seen that the designed diamond airfoil with suction only has a lower maximum overpressure than that of the diamond baseline airfoil, which indicates that the suction near the leading edge of the designed diamond airfoil can reduce the loudness level. What's more, the value of the maximum overpressure is the lowest when the suction slot is located $0.3 \mathrm{~m}$ from the leading edge. The lowest value of the maximum overpressure is $0.668 \mathrm{psf}$. Thus, the optimal location for the suction slot is $\mathrm{X} \_\mathrm{S}=0.3 \mathrm{~m}$.

Opening only an injection slot at different locations, Fig. 5(b) shows the effects of the injection location on the maximum underpressure. The injection slot has a length of $2 \%$ chord. The injection locations range from $0.53 \mathrm{~m}$ to $0.97 \mathrm{~m}$ (i.e. $\mathrm{x}$ _i ranges from $0.53 \mathrm{~m}$ to $0.97 \mathrm{~m}$ ), and the interval is $0.02 \mathrm{~m}$. The mass flow rate at the injection slot is about $2.50 \mathrm{~kg} / \mathrm{s}$. The numerical results show that the injection near the trailing edge of the designed diamond airfoil can reduce the sonic boom, because the designed diamond airfoil with injection only has a higher maximum underpressure than that of the diamond baseline airfoil, shown in Fig. 5(b). It also can be found that when the injection slot is located $0.75 \mathrm{~m}$ from the leading edge, the value of the maximum underpressure is the highest and it is $-0.579 \mathrm{psf}$. Thus, the optimal location for the suction slot is $\mathrm{x}_{\mathrm{i}} \mathrm{i}=0.75 \mathrm{~m}$.

Figure 6(a) is the comparison of the ground sonic boom signature of the optimized diamond airfoil with suction only and the diamond baseline airfoil when a suction slot

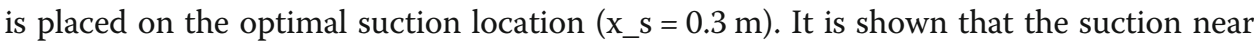
the leading edge of the designed diamond airfoil obviously decreases the maximum

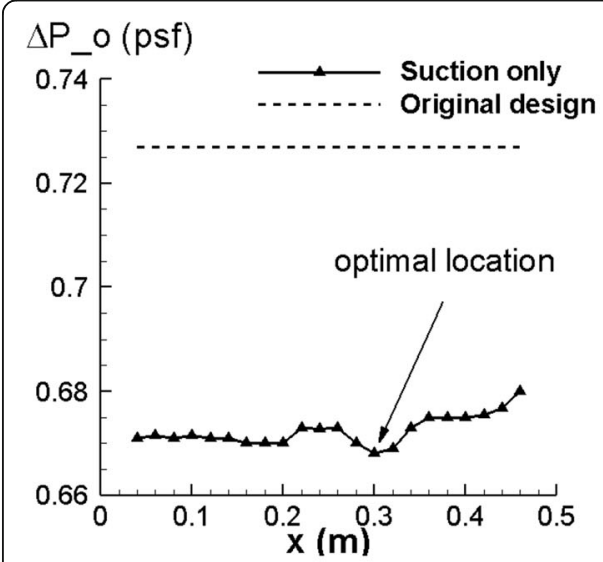

(a)

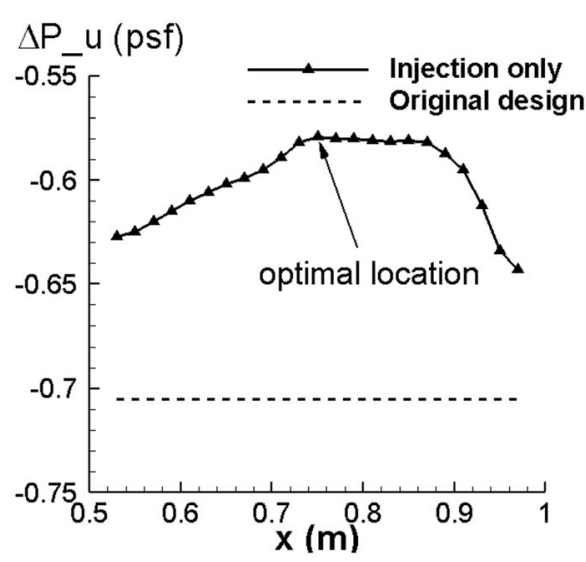

(b)

Fig. 5 The maximum overpressures of the baseline and optimized diamond airfoil a with a suction slot at different locations and $\mathbf{b}$ with an injection slot at different locations 


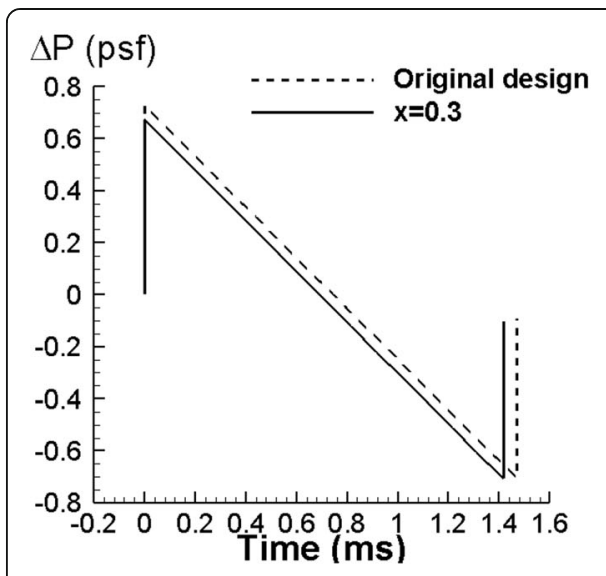

(a)

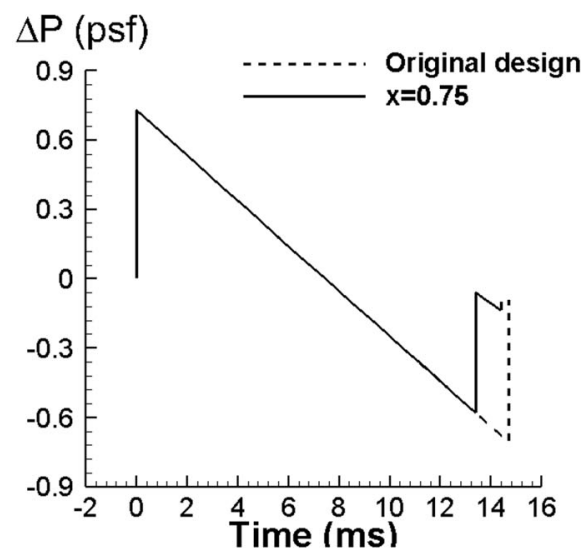

(b)

Fig. 6 Ground boom signatures of the baseline and optimized diamond airfoil a with a suction slot at the optimal location and $\mathbf{b}$ with an injection slot at the optimal location

overpressure, but has little influence on the maximum underpressure. Opening an injection slot at the optimal injection location, Fig. 6(b) shows the comparison of the ground sonic boom signature of the optimized diamond airfoil with injection only and the diamond baseline airfoil. The results show that the injection near the trailing edge of the designed diamond airfoil significantly increases the maximum underpressure, but has little impact on the maximum overpressure.

To compare the performance of the optimized NACA0008 airfoil and the NACA0008 baseline airfoil, the maximum overpressure and the ground sonic boom signatures of the designed and baseline airfoil are plotted in Figs. 7 and 8, respectively. The length of the injection slot is $0.0240 \mathrm{~m}$. In the case of NACA0008 baseline airfoil, the maximum overpressure and maximum underpressure of the ground sonic boom signature are 0.756 psf and $-0.607 \mathrm{psf}$, respectively.

Figure 7(a) shows the maximum overpressures of the optimized NACA0008 airfoil and the NACA0008 baseline airfoil when only a suction slot is opened at different locations. The suction slot has a length of $0.0240 \mathrm{~m}$. The suction locations range from $0.0225 \mathrm{~m}$ to $0.3345 \mathrm{~m}$ (i.e. $\mathrm{x} \_\mathrm{s}$ ranges from $0.0225 \mathrm{~m}$ to $0.3345 \mathrm{~m}$ ), and the interval is $0.0480 \mathrm{~m}$. The mass flow rate at the suction slot is about $-6.8877 \mathrm{~kg} / \mathrm{s}$. The results show that the optimized NACA0008 airfoil with suction only has a lower value of maximum overpressure than that for the NACA0008 baseline airfoil. It also can be seen that the maximum overpressure first decreases and then increases continuously as the suction location moves away from the leading edge. The value of the maximum overpressure is the lowest when the suction slot is located $0.0465 \mathrm{~m}$ from the leading edge. It means that the optimal location for the suction slot is $\mathrm{x} \_\mathrm{s}=0.0465 \mathrm{~m}$.

Figure 7(b) presents the maximum underpressures of the optimized NACA0008 airfoil and the NACA0008 baseline airfoil when only an injection slot is opened at different locations. The length of the suction slot is $0.0240 \mathrm{~m}$. The injection locations range from $0.6195 \mathrm{~m}$ to $0.9555 \mathrm{~m}$ (i.e. $\mathrm{x} \_\mathrm{i}$ ranges from $0.6195 \mathrm{~m}$ to $0.9555 \mathrm{~m}$ ), and the interval is $0.0240 \mathrm{~m}$. The mass flow rate at the suction slot is about $3.35697 \mathrm{~kg} / \mathrm{s}$. The values of maximum underpressures for the optimized NACA0008 airfoil with only an injection slot at different locations are all higher than that for the NACA0008 baseline airfoil. As 


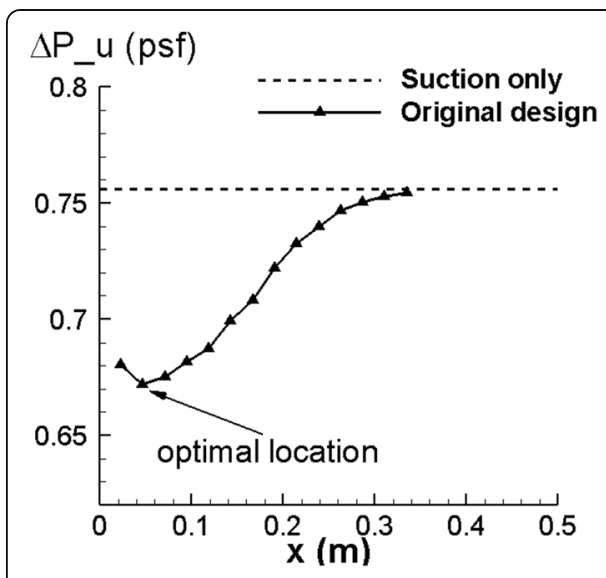

(a)

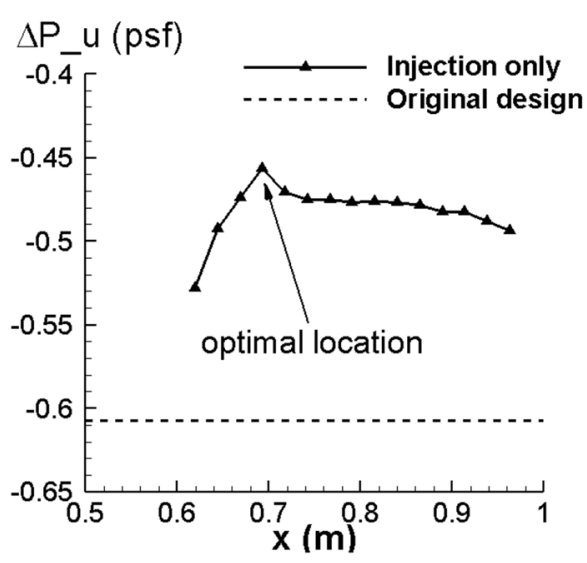

(b)

Fig. 7 The maximum overpressures of the baseline and optimized NACA0008 airfoil a with a suction slot at different locations and $\mathbf{b}$ with an injection slot at different locations

the injection location moves away from the leading edge, the maximum underpressure first increases and then decreases continuously. The value of the maximum underpressure is the highest when the injection slot is located $0.6930 \mathrm{~m}$, which is the optimal location for the injection slot.

When only a suction slot or only an injection slot is placed on the optimal location, Fig. 8(a) and (b) plot the comparison of the ground sonic boom signature for the optimized NACA0008 airfoil and the NACA0008 baseline airfoil. Like the analyses for the optimized diamond airfoil, the suction near the leading edge of the designed NACA0008 airfoil obviously decreases the maximum overpressure, but has little influence on the maximum underpressure. And the injection near the trailing edge of the designed NACA0008 airfoil can significantly increase the maximum uderpressure, but has little effect on the maximum overpressure.

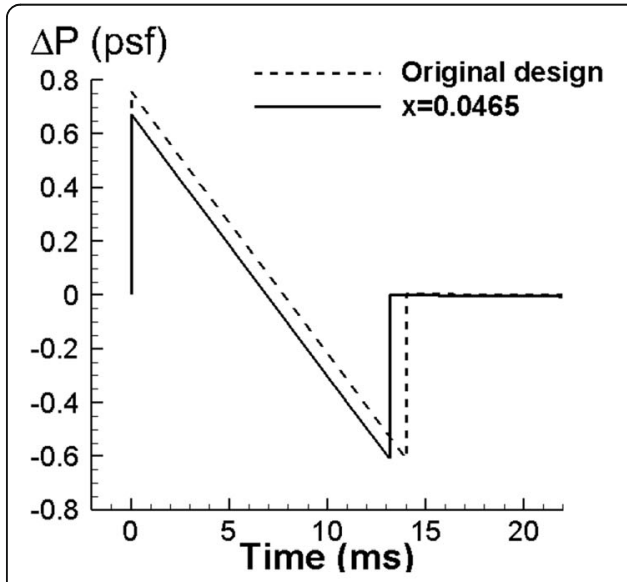

(a)

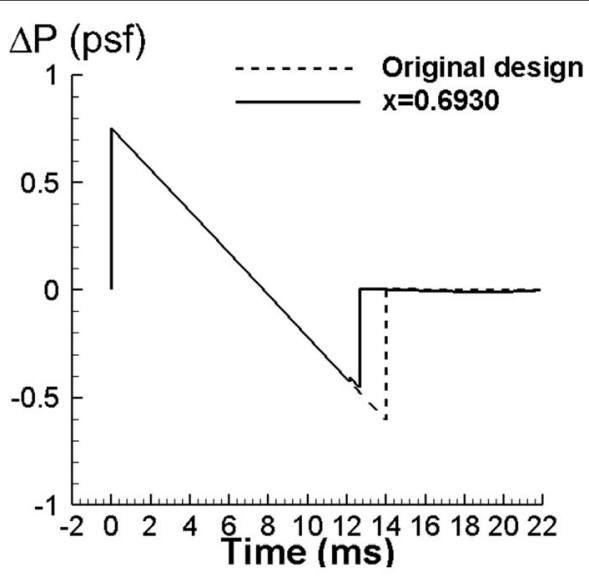

(b)

Fig. 8 Ground boom signatures of the baseline and optimized NACA0008 airfoil a with a suction slot at the optimal location and $\mathbf{b}$ with an injection slot at the optimal location 


\subsection{The effects of mass flow rate}

The mass flow rate at the suction and injection slot is an important parameter, which may affect the final effect of the low-boom and low-drag design method. Here opening the suction and injection slot simultaneously, the effects of mass flow rate on the ground boom signatures and drag coefficients for the optimized diamond and NACA0008 airfoils are studied in Figs. 9, 10, 11, 12, 13, 14 and 15. Studies [40, 41] pointed out that the suction slot size should be larger than the injection slot size, which is easy to be choked when sucked the same amount of injection mass flow. Opening a suction slot with the length of $0.04 \mathrm{c}$ and an injection slot with the length of $0.02 \mathrm{c}$ at the optimal suction location and the optimal injection location found in Section 3.3 respectively, Figs. 9, 10, 11 and 12 present the performance of the optimized diamond airfoil with suction and injection. Placing a suction slot with the length of $0.048 \mathrm{c}$ and an injection slot with the length of $0.024 \mathrm{c}$ at the optimal suction location and the optimal injection location respectively, Figs. 13, 14 and 15 show the performance of the optimized NACA0008 airfoil with suction and injection.

Figure 9 shows the effects of mass flow rate on the maximum overpressure, maximum underpressure, drag coefficient, lift coefficient and lift-drag ratio of the optimized diamond airfoil. It can be seen that with the increasing of the mass flow rate, the maximum overpressure decreases and the maximum underpressure increases. It indicates that the sonic boom intensity continuously decreases with the increase of the mass flow rate. From Fig. 9(c), it can be seen that the drag coefficient continuously increases with the increase of the mass flow rate. From Fig. 9(d) and (e), it can be seen that the lift coefficient and the lift-drag ratio decrease with the increase of the mass flow rate. In fact, as an active flow control technology, the energy input of the pump should be considered when the present low-boom and low-drag method is evaluated. According to the Ref. [40], the power to pump the slotted diamond airfoil can be calculated. Figure 10 shows the power coefficients of the optimized diamond airfoil with different mass flow rates. It can be seen that the power required for the slotted diamond airfoil increases with the increase of the mass flow rate. Therefore, with the combination of the above analysis, the mass flow rate should be increased as much as possible in the allowable range of power consumption to achieve optimal results (i.e. the lowest sonic boom level). When the mass flow rate at the suction and injection slot is $6.5 \mathrm{~kg} / \mathrm{s}$, the maximum overpressure is decreased by $12.87 \%$, the maximum underpressure is increased by $33.83 \%$ and the drag coefficient is reduced by $23.71 \%$. Figure 11 shows the pressure contours of the optimized diamond airfoil with suction and injection, and Fig. 12 shows the comparison of near-field pressure signatures and corresponding ground boom signatures for the baseline and optimized diamond airfoil when the mass flow rate is $6.5 \mathrm{~kg} / \mathrm{s}$. Similar characteristics are obtained from the application of the low-boom and low-drag design method on the NACA0008 airfoil, shown in Figs. 13, 14 and 15. When the mass flow rate at the suction and injection slot is $7.5 \mathrm{~kg} / \mathrm{s}$, the maximum overpressure is decreased by $12.85 \%$, the maximum underpressure is increased by $56.77 \%$, and the drag coefficient is reduced by $17.4 \%$. Figure 14 shows the pressure contours of the optimized NACA0008 airfoil with suction and injection, and Fig. 15 shows the comparison of near-field pressure signatures and corresponding ground boom 


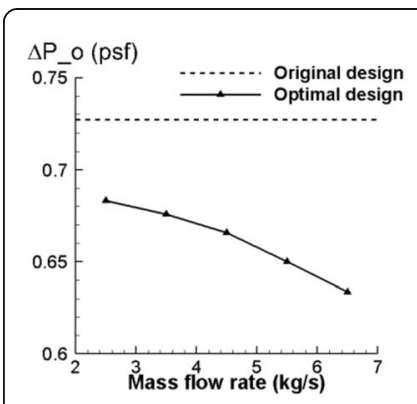

(a)

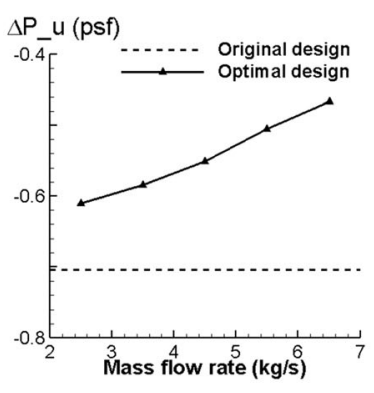

(b)

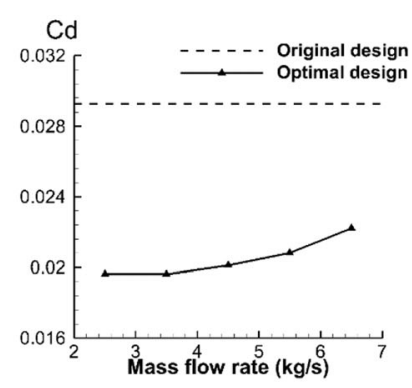

(c)

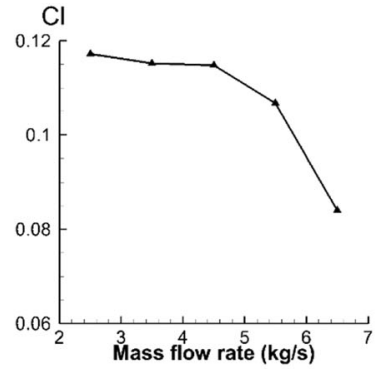

(d)

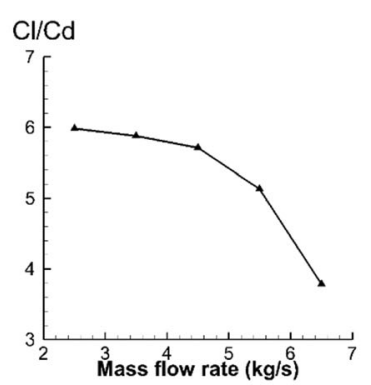

(e)

Fig. 9 The ground boom signatures and drag coefficients for the baseline and optimized diamond airfoil with different mass flow rates. a the maximum overpressure vs the mass flow rate; $\mathbf{b}$ the maximum underpressure vs the mass flow rate; $\mathbf{c}$ the drag coefficient vs the mass flow rate; $\mathbf{d}$ the lift coefficient vs the mass flow rate; e the lift-drag ratio vs the mass flow rate

signatures for the baseline and optimized NACA0008 airfoil when the mass flow rate is $7.5 \mathrm{~kg} / \mathrm{s}$.

In general, increasing the mass flow rate at the suction and injection slot will cause the further reduction of the sonic boom intensity. And the reduction of the sonic boom intensity is more sensitive to the injection near the trailing edge than the suction near the leading edge. The drag coefficient increases with the increase of the mass flow rate. The lift coefficient and lift-drag ratio further decrease as the mass flow rate increases.

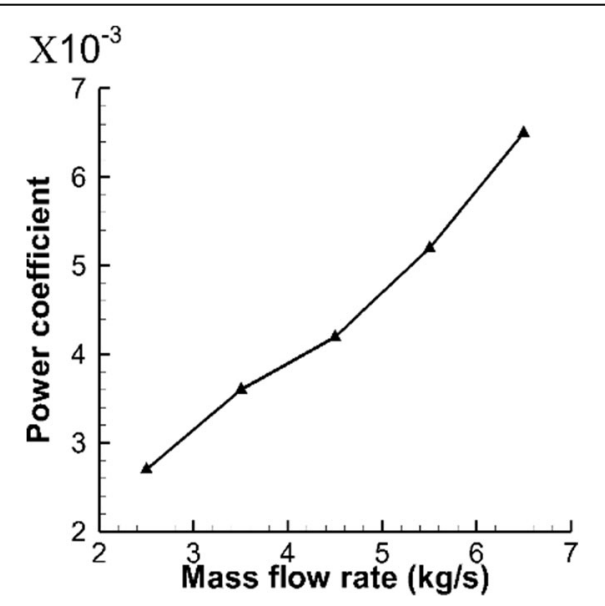

Fig. 10 The power coefficients of the optimized diamond airfoil with different mass flow rates 


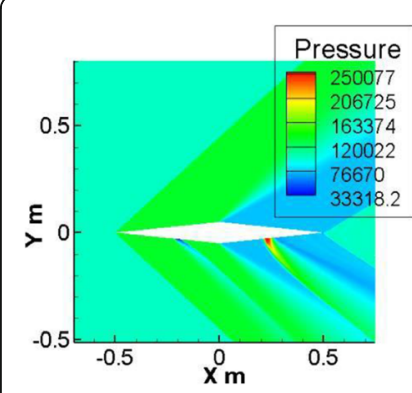

(a)

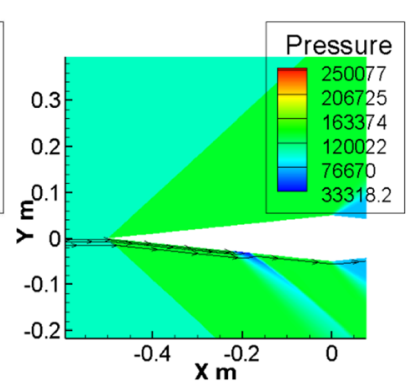

(b)

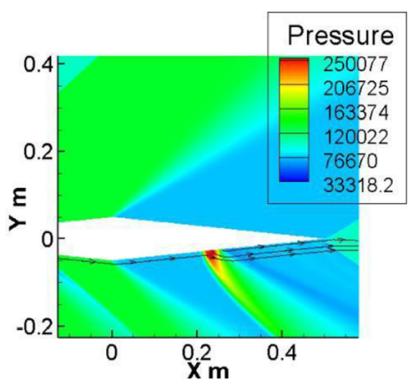

(c)

Fig. 11 Computed pressure contours with streamlines at the mass flow rate $=6.5 \mathrm{~kg} / \mathrm{s}$. a for the whole optimized diamond airfoil $\mathbf{b}$ for the suction slot $\mathbf{c}$ for the injection slot

\subsection{The effects of suction and injection slot size}

To investigate the effects entirely caused by the suction and injection slot size, the same ratio of suction guage pressure to the freestream static pressure $p_{0 \text { suction }} / p_{0 \text { freestream }}=$ 0.9013 is used when the performance of the optimized diamond and NACA0008 airfoils with different suction and injection slot sizes are investigated. To avoid the situation of being choked, the suction slot size should be larger than the injection slot size. For each test case, the suction slot size is $0.02 \mathrm{c}$ larger than the injection slot size for the optimized diamond airfoil, and for the optimized NACA0008 airfoil the suction slot size is $0.024 \mathrm{c}$ larger than the injection slot size. The horizontal axis "Size" in the following figures (i.e. Figs. 16 and 17) all represents the suction slot size.

Figures 16 and 17 show the effects of the suction and injection slot size on the ground boom signatures, drag coefficients, lift coefficients and lift-drag ratios for the optimized diamond airfoil and the optimized NACA0008 airfoil, respectively. In Figs. 16(a), (b) and 17(a), (b), the results show that with the increase of the suction and injection slot size, the maximum overpressure of the ground boom signature firstly decreases and then increases gradually, the maximum underpressure of the ground boom signature firstly increases and then decreases gradually. It indicates that the sonic boom

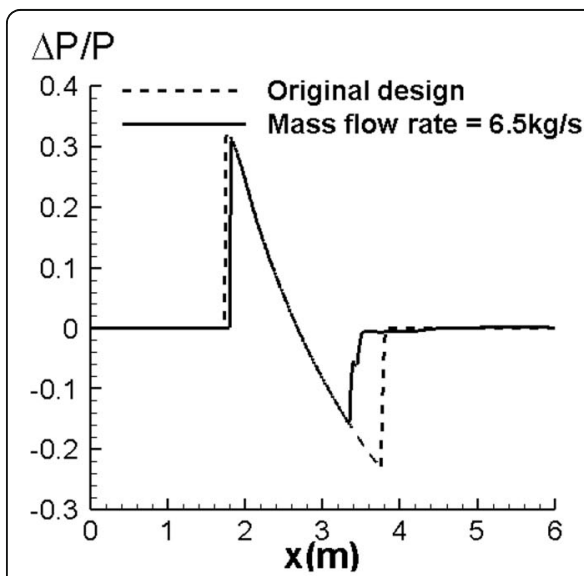

(a)

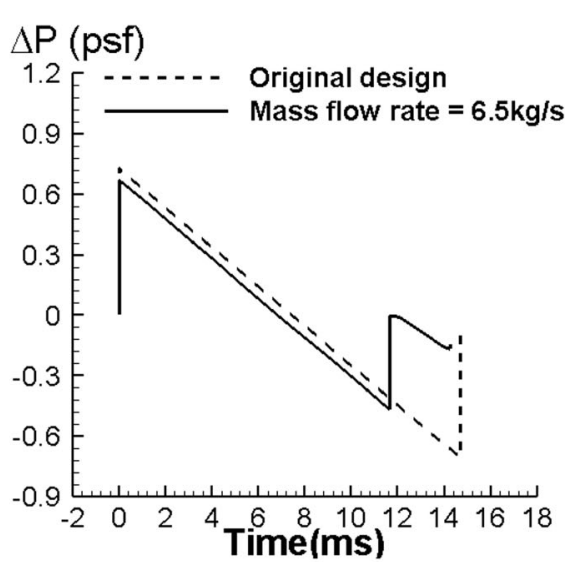

(b)

Fig. 12 The near-field singatures and corresponding ground signatures for the baseline and optimized diamond airfoil at the mass flow rate $=6.5 \mathrm{~kg} / \mathrm{s}$. $\mathbf{a}$ comparison of the near-filed signature $\mathbf{b}$ comparison of the ground boom signature 


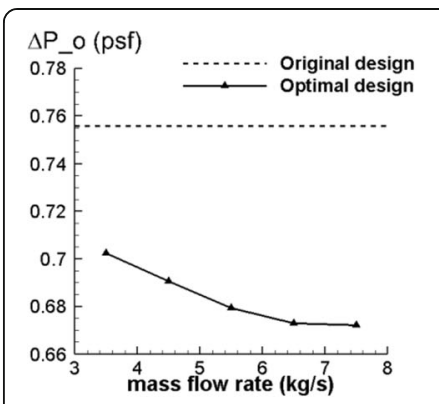

(a)

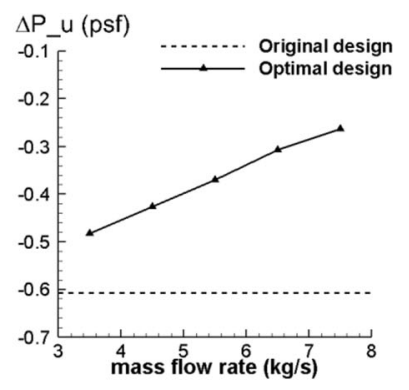

(b)

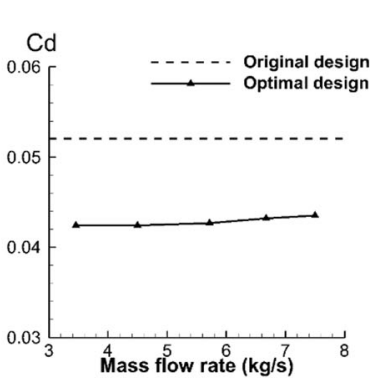

(c)

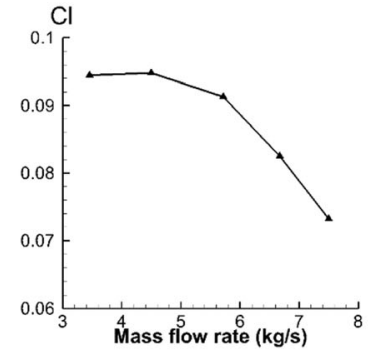

(d)

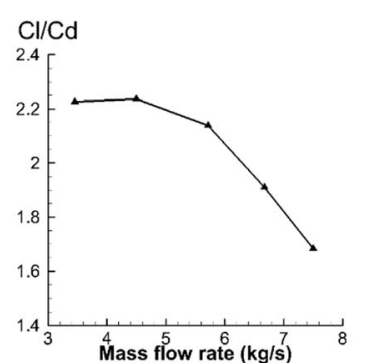

(e)

Fig. 13 The ground boom signatures and drag coefficients for the baseline and optimized NACA0008 airfoil with different mass flow rates. $\mathbf{a}$ the maximum overpressure vs the mass flow rate; $\mathbf{b}$ the maximum underpressure vs the mass flow rate; $\mathbf{c}$ the drag coefficient vs the mass flow rate; $\mathbf{d}$ the lift coefficient vs the mass flow rate; e the lift-drag ratio vs the mass flow rate

intensity decreases with the increasing of the suction and injection slot size. When the suction and injection slot size reaches a certain value, the sonic boom intensity will not decrease but will increase. This is because when the suction slot size is too large, the suction near the leading edge will affect the flow field near the trailing edge and then negatively affect the pressure distribution near the trailing edge. Similarly, when the injection slot size is too large, the injection near the trailing edge has an influence on the flow field near the leading edge and then has a harmful effect on the pressure distribution near the leading edge. There is a minimum sonic boom intensity for the optimized diamond airfoil when the suction slot size is $6 \% \mathrm{c}$ and the injection slot size is $8 \% \mathrm{c}$. And for the optimized NACA0008 airfoil, when the suction slot size is $7.2 \% \mathrm{c}$ and the injection slot size is $9.6 \% \mathrm{c}$ the sonic boom intensity is lowest. Figure 16(c) shows the comparison of the ground boom signature for the baseline and the optimized diamond

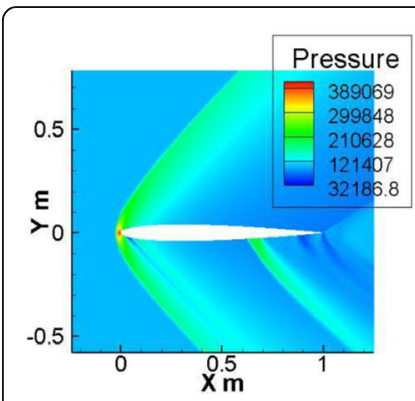

(a)

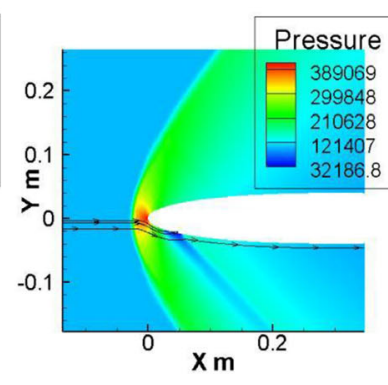

(b)

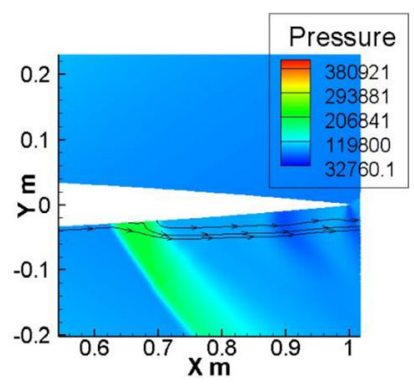

(c)

Fig. 14 Computed pressure contours with streamlines at the mass flow rate $=7.5 \mathrm{~kg} / \mathrm{s}$. a for the whole optimized NACA0008 airfoil $\mathbf{b}$ for the suction slot $\mathbf{c}$ for the injection slot 


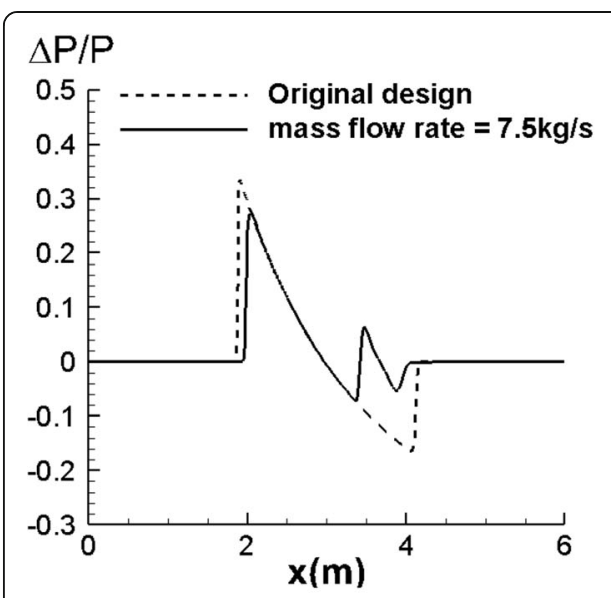

(a)

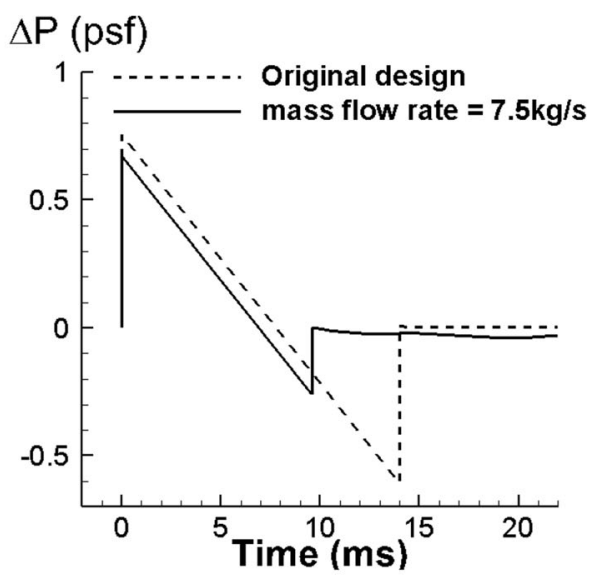

(b)

Fig. 15 The near-field signatures and corresponding ground signatures for the baseline and optimized NACA0008 airfoil at the mass flow rate $=7.5 \mathrm{~kg} / \mathrm{s}$. a comparison of the near-field signature $\mathbf{b}$ comparison of the ground boom signature

airfoil when the suction slot size is $6 \%$ c. It can be shown that the maximum overpressure is decreased by $9.95 \%$, and the maximum underpressure is increased by $68.20 \%$. Figure 17(c) shows the comparison of the ground boom signature for the baseline and the optimized NACA0008 airfoil when the suction slot size is $7.2 \% \mathrm{c}$. It can be seen that the maximum overpressure is decreased by $16.10 \%$, and the maximum underpressure is increased by $74.28 \%$. Figures $16(\mathrm{~d})$ and $17(\mathrm{~d})$ show the effects of the suction and injection slot size on the drag coefficient for the optimized diamond airfoil and the optimized NACA0008 airfoil, respectively. The results indicate that the drag coefficient continuously decreases with the increment of the suction and injection slot size. The drag coefficient is decreased by $25.02 \%$ for the optimized diamond airfoil when the suction slot size is 6\%c. For the optimized NACA0008 airfoil when the suction slot size is $7.2 \% \mathrm{c}$, the drag coefficient is reduced by $23.15 \%$. Figures $16(\mathrm{e})$, (f) and 17(e), (f) show the effects of the suction and injection slot size on the lift coefficients and lift-drag ratios.

The results shown in Figs. 16 and 17 indicate that the increment of the suction and injection slot size can remarkably reduce the sonic boom intensity and the drag coefficients. However, the sonic boom intensity will not decrease but will increase when the suction and injection slot size reaches a certain value. On the other hand, the too large suction and injection slot size also has a harmful effect on the stiffness of the wing in the engineering practice. Thus, the appropriate suction and injection slot size should be chosen when the low-boom and low-drag design method is used.

\subsection{The effects of attack angle}

The effects of angles of attack on the ground boom signatures, drag coefficients, lift coefficients and lift-drag ratios for the baseline and optimized diamond airfoil are shown in Fig. 18. And Fig. 19 shows the ground boom signatures, drag coefficients, lift coefficients and lift-drag ratios for the baseline and optimized NACA0008 airfoil at different angles of attack. For the optimized diamond and NACA0008 airfoils with different 


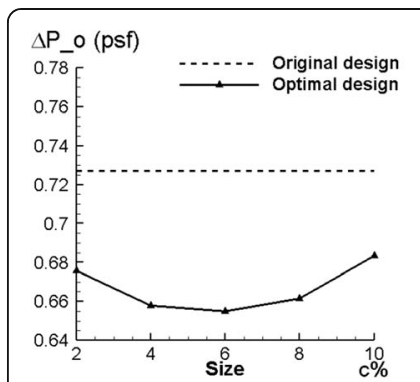

(a)

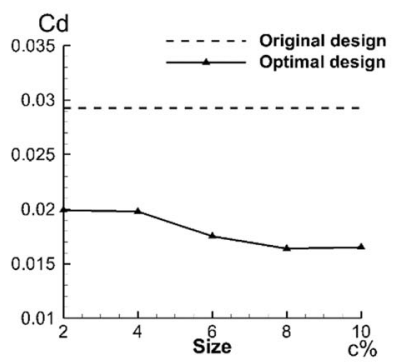

(d)

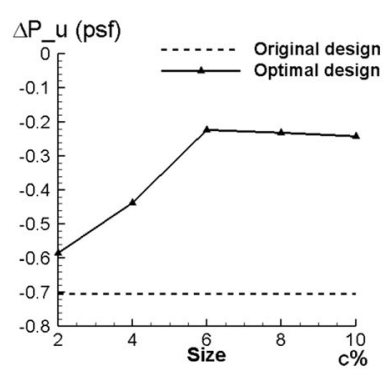

(b)

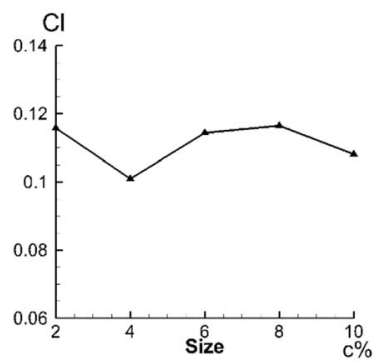

(e)

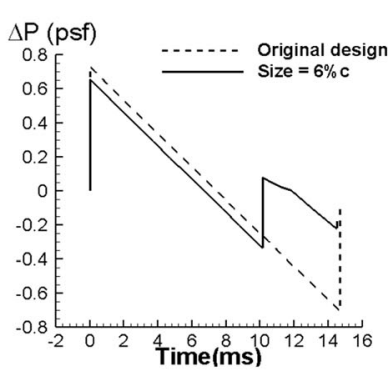

(c)

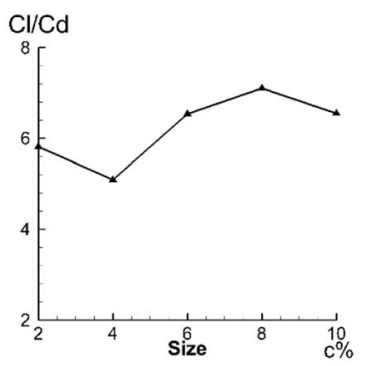

(f)

Fig. 16 The ground boom signatures and drag coefficients for the baseline and optimized diamond airfoil with different suction and injection slot sizes. $\mathbf{a}$ the maximum overpressure vs the slot size; $\mathbf{b}$ the maximum underpressure vs the slot size; c comparison of the ground boom signature at the suction slot size $=6 \%$; $\mathbf{d}$ the drag coefficient vs the slot size; e the lift coefficient vs the slot size; $\mathbf{f}$ the lift-drag ratio vs the slot size

angles of attack, the suction slot and the injection slot are respectively located at their corresponding optimal locations found in Section 3.3 and the mass flow rate at the suction and injection slot is $3.5 \mathrm{~kg} / \mathrm{s}$.

For the baseline diamond and NACA0008 airfoils, with the increase of the angle of attack, the maximum overpressure and the maximum underpressure both increase. What's more, the drag coefficient also continuously increases. The results presented in Figs. 18 and 19 show that compared to the results of the baseline airfoil, the maximum overpressure is slightly decreased and the maximum underpressure is significantly increased at different angles of attack after opening a suction slot near the leading edge and an injection slot near the trailing edge simultaneously. It indicates that the reduction of the sonic boom intensity is more sensitive to the injection near the trailing edge than the suction near the leading edge. It also means that the low-boom and low-drag design method is effective not only when the angle of attack is zero but also at the non-zero attack angle. For the optimized diamond airfoil when the angle of attack is $4^{\circ}$, the maximum overpressure is decreased by $16.10 \%$, the maximum underpressure is increased by $74.28 \%$, and the drag coefficient is decreased by $25.58 \%$. For the optimized NACA0008 airfoil when the angle of attack is $2^{\circ}$, the maximum overpressure is decreased by $16.10 \%$, the maximum underpressure is increased by $74.28 \%$, and the drag coefficient is decreased by $23.64 \%$. It also should be noted that the maximum underpressure will not increase but decrease when the angle of attack is $5^{\circ}$ for the optimized diamond airfoil and when the angle of attack is $3^{\circ}$ for the optimized NACA0008 airfoil. This indicates that at the relatively large angle of attack, the injection near the trailing edge will not reduce the sonic boom but increase the sonic boom intensity. The results shown in Figs. 18(d) and 19(d) indicate that under different attack angles, drag 


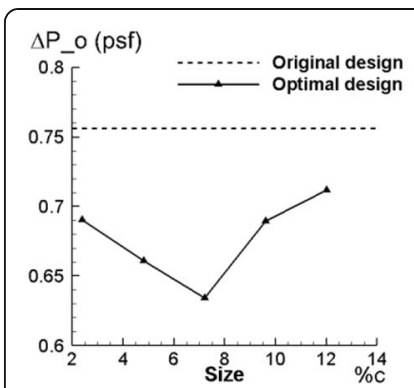

(a)

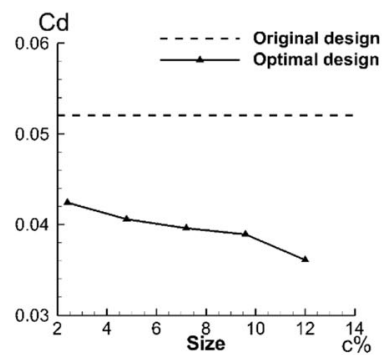

(d)

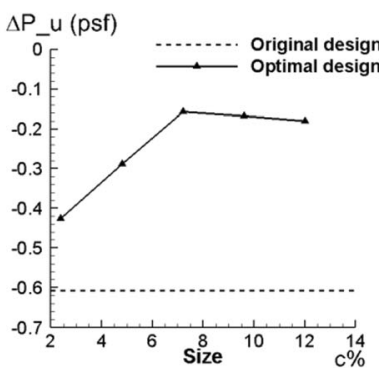

(b)

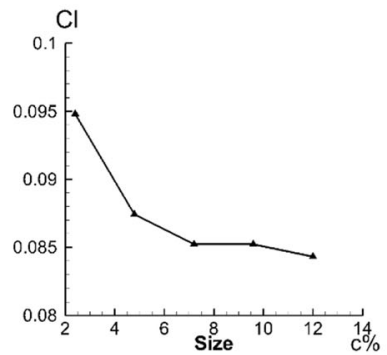

(e)

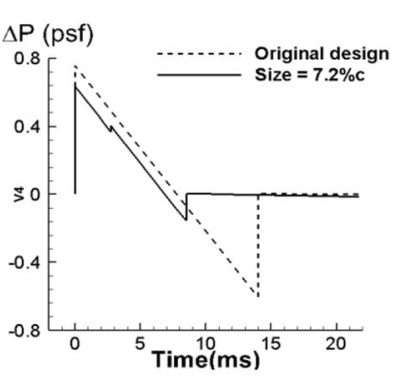

(c)

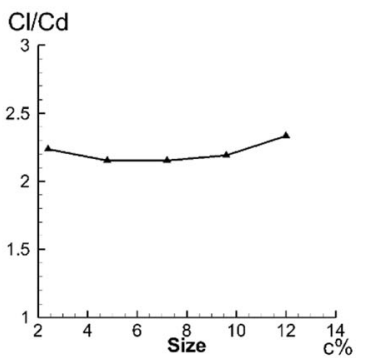

(f)

Fig. 17 The ground boom signatures and drag coefficients for the baseline and optimized NACA0008 airfoil with different suction and injection slot sizes. $\mathbf{a}$ the maximum overpressure vs the slot size; $\mathbf{b}$ the maximum underpressure vs the slot size; $\mathbf{c}$ comparison of the ground boom signature at the suction slot size $=7.2 \% \mathrm{c}$; $\mathbf{d}$ the drag coefficient vs the slot size; $\mathbf{e}$ the lift coefficient vs the slot size; $\mathbf{f}$ the lift-drag ratio vs the slot size

coefficients will decrease after opening a suction slot near the leading edge and an injection slot near the trailing edge simultaneously. What's more, the results shown in Figs. 18(e), (f) and 19(e),(f) indicate that the low-boom and low-drag design method will not introduce a severe aerodynamic performance penalty and even the lift-drag ratios will increase after using this method under some circumstances shown in Fig. 18(f).

From the above analysis, we can see that the low-boom and low-drag design method is effective not only when the angle of attack is zero but also at non-zero attack angles, and the method is suitable for the supersonic aircraft within the range of small attack angles.

In order to confirm that the near-field location at which the ground signatures are propagated from the near-field pressure distributions is appropriate, here we choose different near-field locations, as shown in Fig. 20. For the optimized diamond airfoil, a suction slot with the length of $0.04 \mathrm{c}$ and an injection slot with the length of $0.02 \mathrm{c}$ at the optimal suction location and the optimal injection location found in Section 3.3 are opened. And the mass flow rate at the suction and injection slot is $6.5 \mathrm{~kg} / \mathrm{s}$. For the optimized NACA0008 airfoil, a suction slot with the length of $0.048 \mathrm{c}$ and an injection slot with the length of $0.024 \mathrm{c}$ at the optimal suction location and the optimal injection location are opened. And the mass flow rate at the suction and injection slot is $7.5 \mathrm{~kg} / \mathrm{s}$. It can be seen in Fig. 20 that the maximum overpressures and the maximum underpressures of the ground sonic boom signatures from $H / L=2$ are nearly the same as that from $\mathrm{H} / \mathrm{L}=5$ and $\mathrm{H} / \mathrm{L}=7$. It means that the near-field location (i.e. $\mathrm{H} / \mathrm{L}=2$ ) chosen in this paper is appropriate.

To further verify the feasibility of the present method, the meaningful comparisons on the sonic boom signatures and drag coefficients at the same total lift condition 


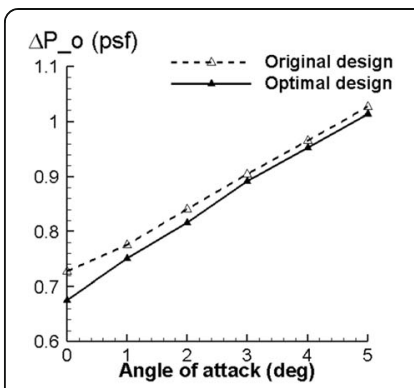

(a)

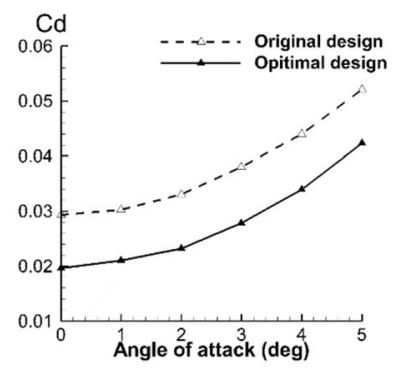

(d)

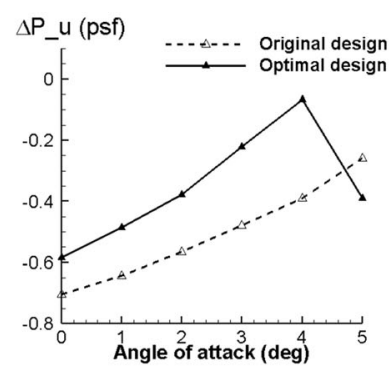

(b)

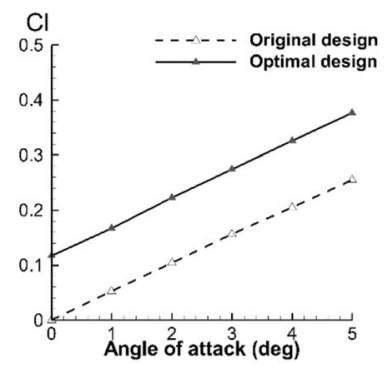

(e)

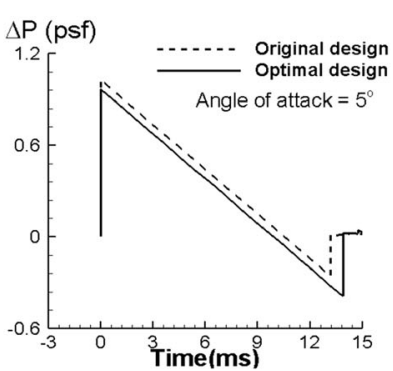

(c)

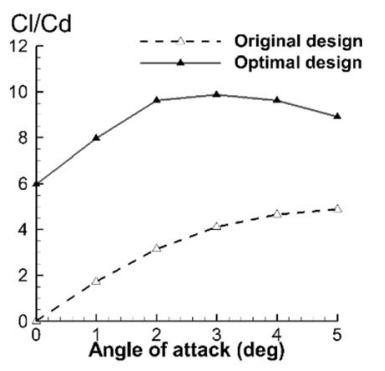

(f)

Fig. 18 The ground boom signatures and drag coefficients for the baseline and optimized diamond airfoil with different angles of attack. $\mathbf{a}$ the maximum overpressure vs the angle of attack; $\mathbf{b}$ the maximum underpressure vs the angle of attack; $\mathbf{c}$ comparison of the ground boom signature at the angle of attack= $5^{\circ} ; \mathbf{d}$ the drag coefficient vs the angle of attack; e the lift coefficient vs the angle of attack; $\mathbf{f}$ the lift-drag ratio vs the angle of attack

should be made. Unless otherwise specified, the simulation conditions considered here are basically the same as that in the above analysis, and the specific conditions can be seen in the first paragraph in Section 3. Firstly, the diamond airfoil is selected as the baseline airfoil. For baseline diamond airfoil, the attack angle is 1.62 degrees. The lift coefficient $\mathrm{Cl}$ calculated by CFD is 0.0841 , and the drag coefficient is 0.0294 . For the corresponding slotted airfoil, the attack angle is zero. A suction slot with the length of $0.04 \mathrm{c}$ and an injection slot with the length of $0.02 \mathrm{c}$ are opened at the optimal suction location and the optimal injection location found in Section 3.3, respectively. The mass flow rate at the suction and injection slot is $6.5 \mathrm{~kg} / \mathrm{s}$. The lift coefficient $\mathrm{Cl}$ calculated by CFD is also 0.0841 , which is the same as that for the baseline airfoil. The drag coefficient is 0.0222 , which is reduced by $24.5 \%$. Figure 21 (a) shows the comparison of ground boom signatures for the baseline diamond airfoil and the corresponding slotted airfoil. It can be seen that compared with results of the baseline diamond airfoil, the maximum overpressure of the slotted airfoil is decreased by $21.2 \%$, and the maximum underpressure is increased by $24.2 \%$. Then, the NACA0008 airfoil is selected as the airfoil baseline. In the case of the baseline NACA0008 airfoil, the angle of attack is 1.53 degrees. The lift coefficient and drag coefficient calculated by CFD are 0.0732 and 0.0520 , respectively. Placing a suction slot with the length of $0.048 \mathrm{c}$ and an injection slot with the length of $0.024 \mathrm{c}$ at the optimal suction and the optimal injection location respectively, the lift coefficient of the slotted airfoil is also 0.0732 when the mass flow rate at the suction and injection slot is $7.5 \mathrm{~kg} / \mathrm{s}$. The drag coefficient is 0.0435 , which is decreased by $16.4 \%$. Figure 21 (b) shows the comparison of ground boom signatures for the baseline NACA0008 airfoil and the corresponding slotted airfoil. It can be seen that 


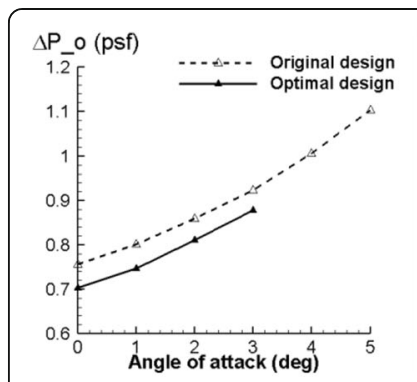

(a)

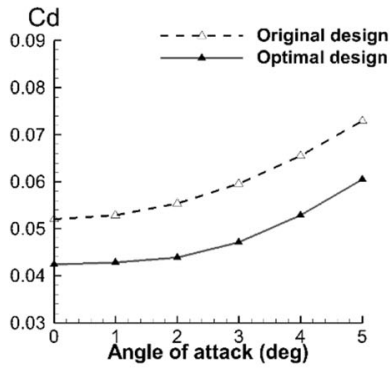

(d)

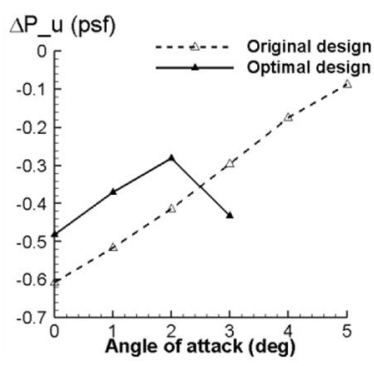

(b)

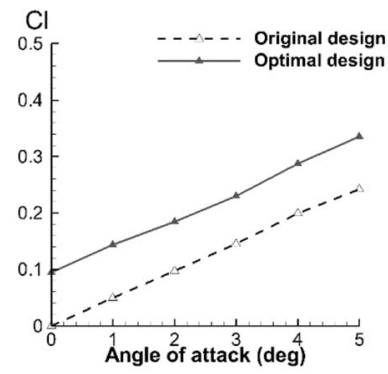

(e)

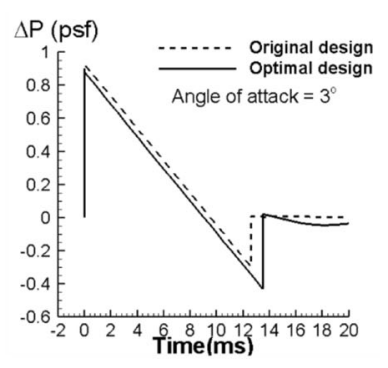

(c)

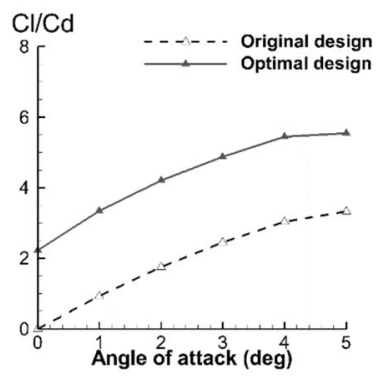

(f)

Fig. 19 The ground boom signatures and drag coefficients for the baseline and optimized NACA0008 airfoil with different angles of attack. $\mathbf{a}$ the maximum overpressure vs the angle of attack; $\mathbf{b}$ the maximum underpressure vs the angle of attack; c comparison of the ground boom signature at the angle of attack = $3^{\circ}$; $\mathbf{d}$ the drag coefficient vs the angle of attack; e the lift coefficient vs the angle of attack; $\mathbf{f}$ the lift-drag ratio vs the angle of attack

compared with results of the baseline NACA0008 airfoil, the maximum overpressure of the slotted airfoil is decreased by $20.1 \%$, and the maximum underpressure is increased by $51.4 \%$. From the above analysis, we can see that at the same total lift condition, the present method still can reduce the sonic boom level and drag.

From the above analysis, it can be seen that all the test cases are just for inviscid cases. Here we study the effect of the low-boom and low-drag design method when the viscousity effect is considered. The diamond airfoil is selected as the baseline airfoil. Densifying the grids near the model, the boundary layer grids are generated. The height of the first mesh cell in the boundary layer is determined with $Y+\leq 1$. The viscous computations are performed at $M a_{\infty}=1.7, \operatorname{Re}=5.284 \times 10^{7}$, with one-equation SparatAllmaras turbulence model. In order to more precisely verify the feasibility of the present method, the ground boom signatures and drag coefficients of the baseline airfoil are compared with that of the slotted design at the same total lift. The far-field propagation conditions are the same as that in above inviscid cases. For the baseline diamond airfoil, the attack angle is 1.65 degrees. The lift coefficient $\mathrm{Cl}$ calculated by CFD is 0.0862 , and the drag coefficient is 0.0333 . For the airfoil with suction and injection slots, the attack angle is zero. A suction slot with the length of $0.04 \mathrm{c}$ and an injection slot with the length of $0.02 \mathrm{c}$ are opened at the optimal suction location and the optimal injection location found in Section 3.3, respectively. The mass flow rate at the suction and injection slot is $6.5 \mathrm{~kg} / \mathrm{s}$. The lift coefficient $\mathrm{Cl}$ calculated by CFD is also 0.0862, which is the same as that for the baseline airfoil. The drag coefficient is 0.0289 , which is reduced by $13.1 \%$. Figure 22 shows the comparison of near-field pressure signatures and corresponding ground boom signatures for the baseline airfoil and 


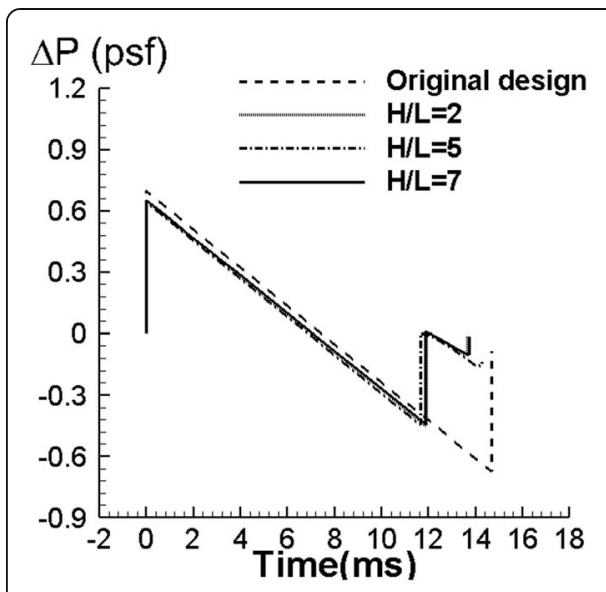

(a)

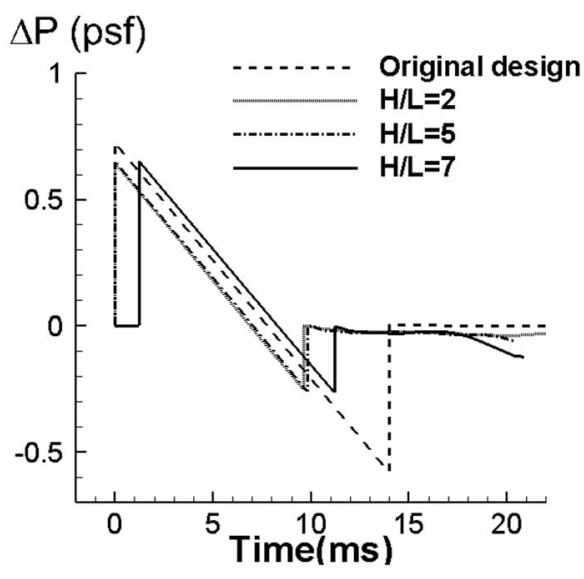

(b)

Fig. 20 The ground boom signatures at $H / L=2,5,7$ for $\mathbf{a}$ the baseline and optimized diamond airfoil and b the baseline and optimized NACA0008 airfoil

the airfoil with suction and injection slots. It can be seen that compared with the results of the baseline airfoil, the maximum overpressure of the slotted airfoil is decreased by $20.27 \%$, and the maximum underpressure is increased by $11.35 \%$.

In order to verify the feasibility of the present method in 3-D case, a wing based on the airfoil of NACA0008 is adopted as the baseline wing. Figure 23 shows the geometrical properties of the wing with suction and injection slots. As shown in Fig. 23, the tip chord is $c_{r}=1 \mathrm{~m}$, the chord length of the wing tip is $c_{t}=0.25 \mathrm{~m}$, the leading edge sweepback angle is $\Lambda=60^{\circ}$, the length of the semispan is $1 / 2 b=2 \mathrm{~m}$, and the taper ratio of the wing is $c_{t} / c_{r}=4$.

When the present low-boom and low-drag method is applied on the 3-D wing, a suction slot near the leading edge and an injection slot near the trailing edge are opened as shown in Fig. 23(a). For each airfoil section, the ratio of the distance between the suction slot and the leading edge to the local chord length is the same as each other, i.e., $x$ ${ }_{-} s 3 d / c=$ const. $c$ is the local chord length, for example, $c=c_{r}$ for the airfoil at the wing root and $c=c_{t}$ for the airfoil at the wingtip. Similarly, for each airfoil section, the ratio of the distance between the injection slot and the leading edge to the local chord length is the same as each other, i.e., $x_{-} i 3 d / c=$ const. The ratios of $x_{-} s 3 d / c=4.65 \%$ and $x_{-}$ $i 3 d / c=69.3 \%$ are selected. Shown in Fig. 23(b), the size of the suction slot is equal to that of the injection slot, and they are both denoted as $d$. For an arbitrary airfoil section, the size of the suction or injection slot is $2.4 \%$ c. For example, $d=0.024 \mathrm{~m}$ at the wing root and $d=0.006 \mathrm{~m}$ at the wingtip.

The hybrid meshes are generated for inviscid simulations for the baseline wing and the wing with suction and injection slots, as shown in Fig. 24. The local mesh refinement approach is adopted to ensure the accuracy of computations near the suction and injection slot. For the wing with suction and injection slots, the node and cell numbers are 3,120,363 and 10,644,795, respectively. The mesh convergence analysis has proved that the present mesh can provide satisfactory results, and the mesh convergence analysis is not shown here. The boundary condition of the suction is set as the pressure outlet condition, and the boundary condition of the injection is simulated with the velocity inlet condition. By adjusting the velocity value of the jet at the velocity inlet 


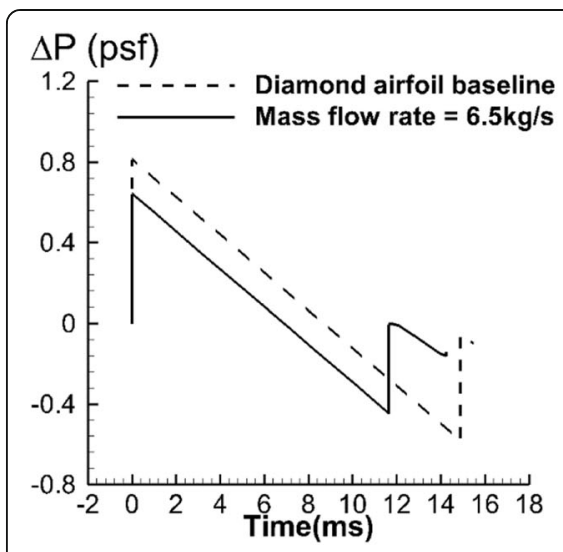

(a)

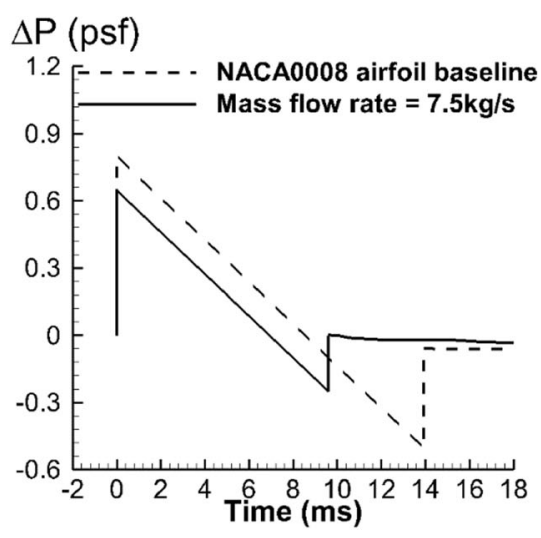

(b)

Fig. 21 The comparison of ground boom signatures a for the diamond airfoil baseline and the optimized diamond airfoil at the mass flow rate $=6.5 \mathrm{~kg} / \mathrm{s} \mathbf{b}$ for the NACA0008 airfoil baseline and the optimized NACA0008 airfoil at the mass flow rate $=7.5 \mathrm{~kg} / \mathrm{s}$

condition, the mass flow passing the injection slot is controlled to be the same as that sucked in the suction slot. For the far-field propagation, the ground signatures for the wing baseline and the designed wing are propagated with FL-BOOM from the nearfield pressure distributions calculated with CFD at two locations, i.e. the intersection of surface $Z=-2 \mathrm{~m}$ and surface $\mathrm{Y}=1.125 \mathrm{~m}$, and the intersection of surface $Z=-2 \mathrm{~m}$ and surface $\mathrm{Y}=1.5 \mathrm{~m}$. The real aircraft is assumed at an altitude of $16764 \mathrm{~m}$ and in a nowind U.S. Standard Atmosphere.

Here the Mach number $\mathrm{Ma}=1.7$ is selected to conduct the simulations. For the baseline wing, the angle of attack is $0.863 \mathrm{deg}$. The lift coefficient calculated by CFD is 0.0314 , and the drag coefficient is 0.0183 . To achieve the same lift, the attack angle of the wing with suction and injection is zero. The mass flow rate at the suction and injection slot is $3 \mathrm{~kg} / \mathrm{s}$. For the slotted wing, the drag coefficient calculated by CFD is 0.0169 , which is decreased by $7.65 \%$. Figure 25 shows the comparison of ground boom signatures for the baseline wing and the wing with suction and injection slots. From Fig. 25(a), it can be seen that when the near-field boom signatures at the intersection of surface $\mathrm{Z}=-2 \mathrm{~m}$ and surface $\mathrm{Y}=1.125 \mathrm{~m}$ propagate to the ground, the maximum overpressure of the ground boom signature is decreased by $5.62 \%$, and the maximum underpressure is increased by $25.4 \%$. Shown in Fig. 25(b), it can be seen that when the near-field boom signatures at the intersection of surface $\mathrm{Z}=-2 \mathrm{~m}$ and surface $\mathrm{Y}=1.125$ $\mathrm{m}$ propagate to the ground, the maximum overpressure of the ground boom signature is decreased by $4.14 \%$, and the maximum underpressure is increased by $20.7 \%$. In our present study, we carried a preliminary study on the present low-boom and low-drag method for supersonic aircraft. We focus on the applications of the present low-boom and low-drag method on the 2-D airfoil and the 3-D wing. In our next work, we will study the application of the present low-boom and low-drag method on the whole aircraft.

\section{Conclusions}

A novel concept for supersonic aircraft to reduce the sonic boom and drag coefficient was developed and investigated, wherein a suction slot near the leading edge and an 


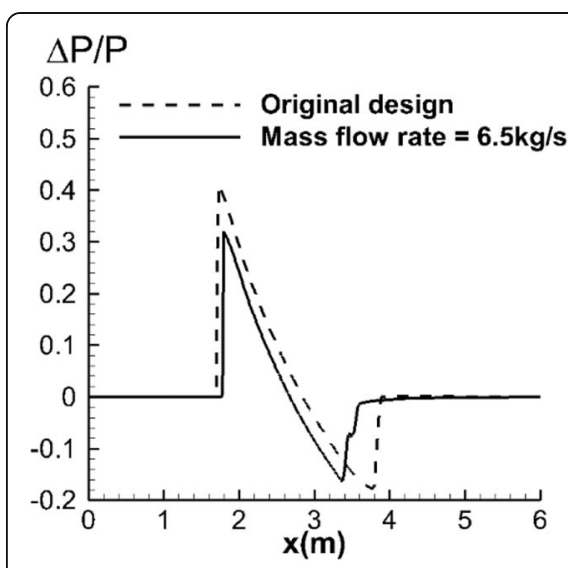

(a)

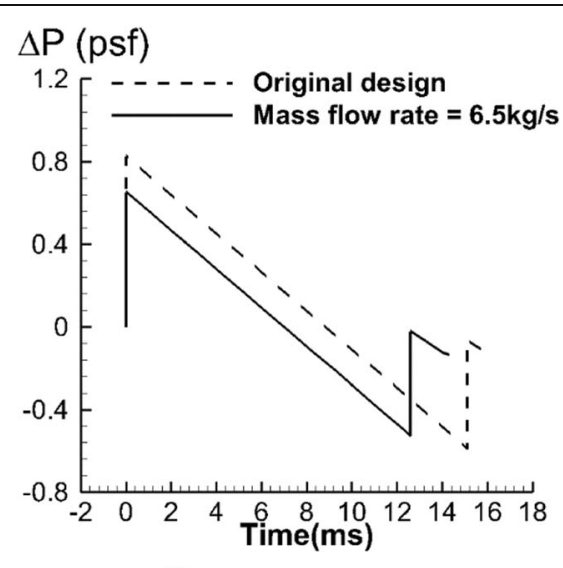

(b)

Fig. 22 The near-field signatures and corresponding ground signatures for the baseline airfoil and the optimized diamond airfoil at the mass flow rate $=6.5 \mathrm{~kg} / \mathrm{s}$. $\mathbf{a}$ comparison of the near-field signature $\mathbf{b}$ comparison of the ground boom signature

injection slot near the trailing edge on the airfoil suction surface are opened. For energy saving, the suction and injection slots can be selectively opened, which are opened when the supersonic aircraft flies over the city but are closed when the aircraft flies over the sea. To make sure of a zero net mass flux flow control, the mass flow sucked in near the leading edge is equal to the mass flow injected near the trailing edge. The diamond and NACA0008 airfoils are adopted as the baseline airfoil to verify the capability of the proposed design method. Using the structured grid, the near field pressure

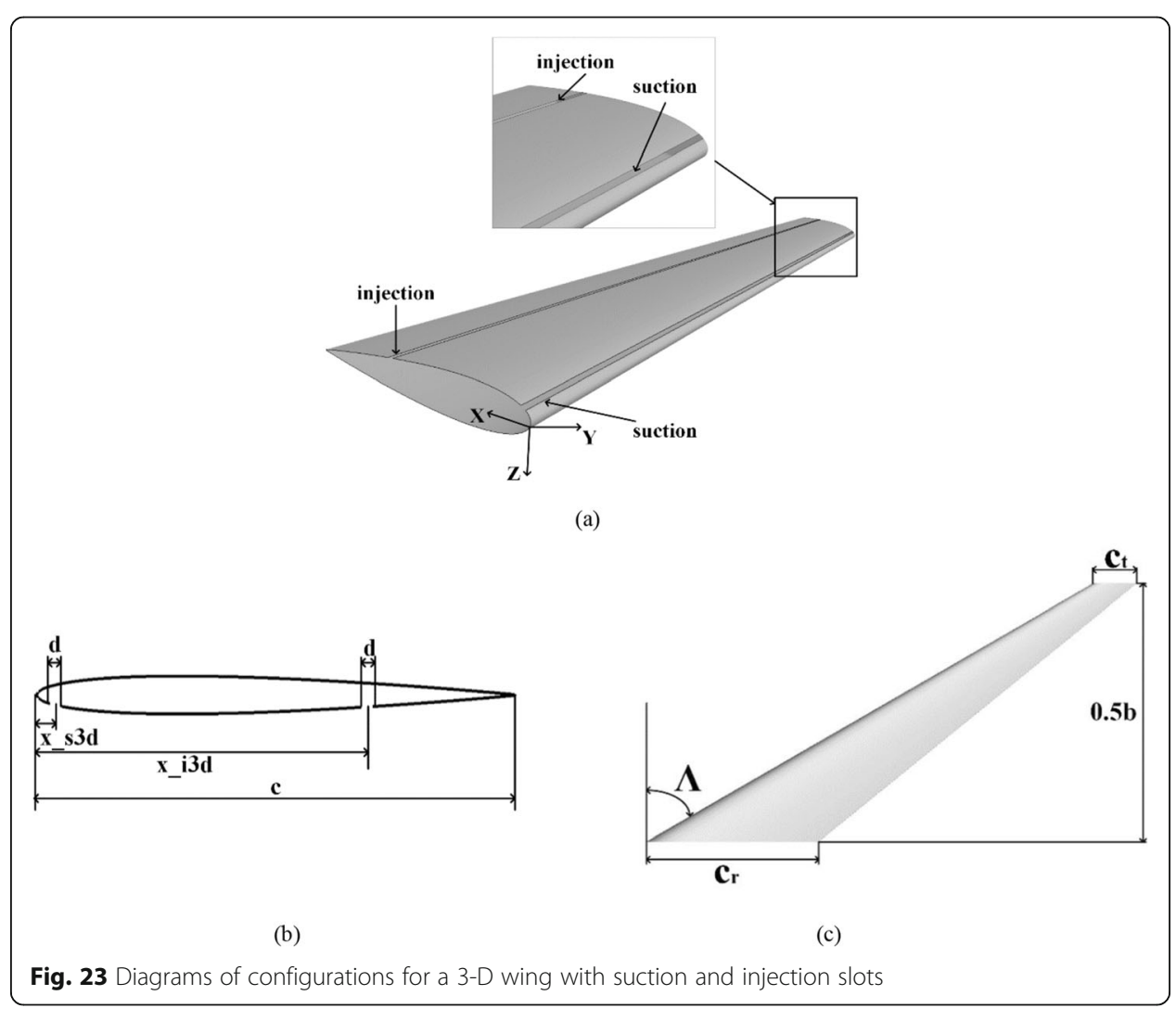




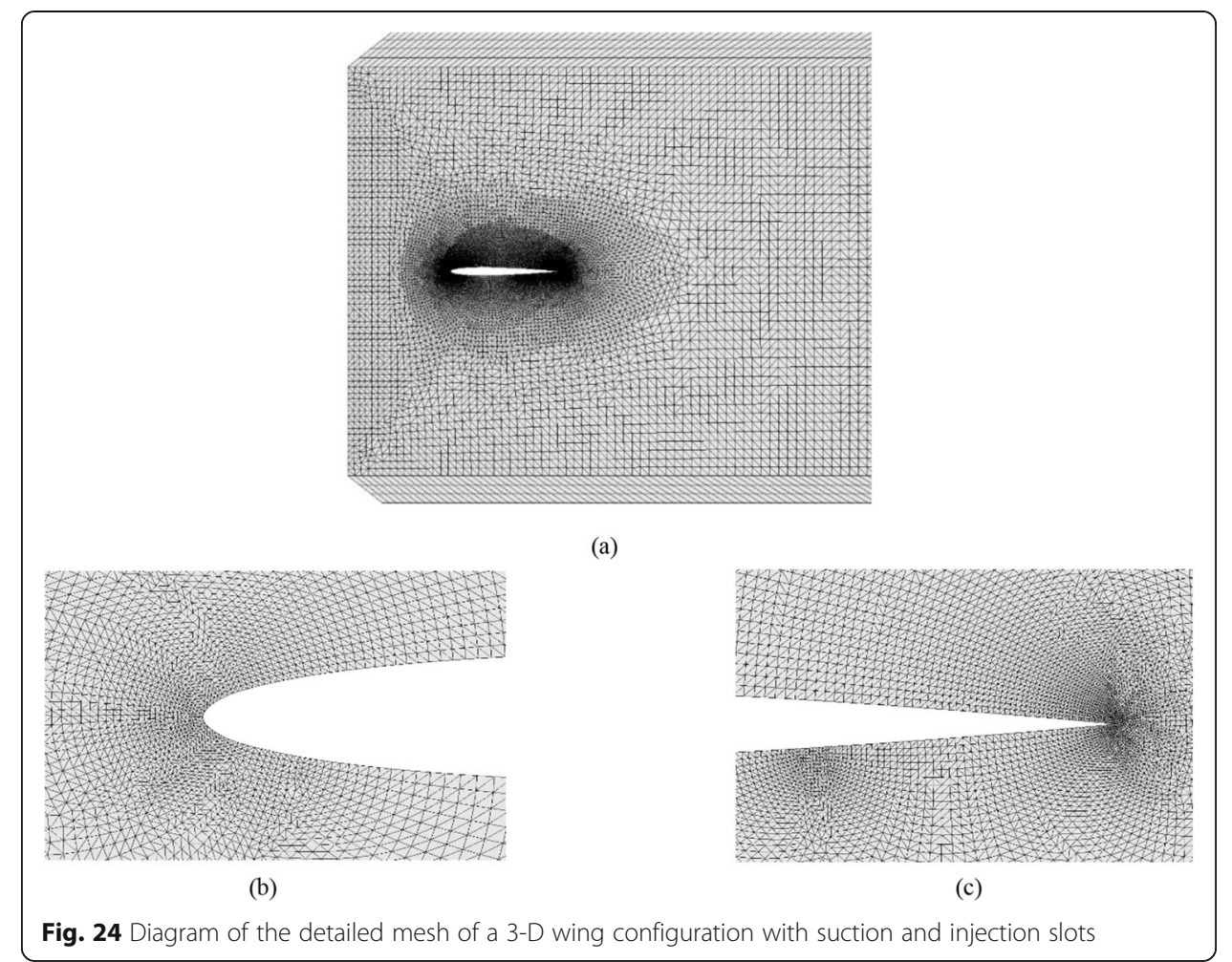

distribution is obtained by solving the two-dimensional Euler equations. The ground sonic-boom signatures are generated by a sonic boom signal propagation and analysis tool FL-BOOM.

The effects of the suction and injection location, the suction and injection slot size, the mass flow rate and the attack angle on the ground boom signature and drag coefficient are studied in detail. Several conclusions can be drawn as follows:

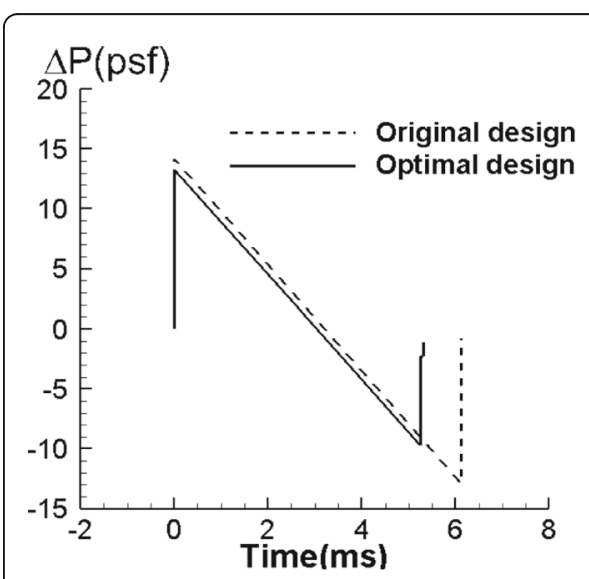

(a) $\mathrm{Y}=1.125 \mathrm{~m}$

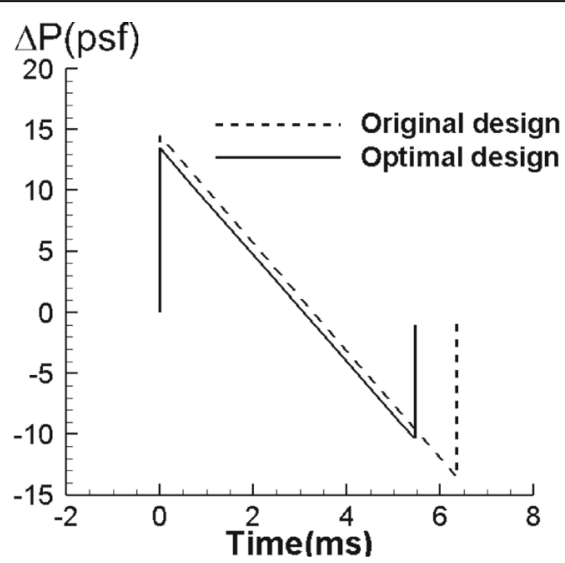

(b) $\mathrm{Y}=1.5 \mathrm{~m}$

Fig. 25 The ground boom signatures of the baseline wing and the optimized wing from the intersection of surface $Z=-2 \mathrm{~m}$ and $\mathbf{a}$ surface $Y=1.125 \mathrm{~m}$ b $Y=1.5 \mathrm{~m}$ 
(1) The low-boom and low-drag design method for supersonic aircraft was shown to be effective in reducing the sonic boom and drag coefficient.

(2) From the viewpoint of aerodynamics, opening the suction and injection slots will not introduce a severe aerodynamic performance penalty and even increase the liftdrag ratio under some circumstances.

(3) Increasing the mass flow rate at the suction and injection slot will cause the further reduction of the sonic boom intensity.

(4) The reduction of the sonic boom intensity is more sensitive to the injection near the trailing edge than the suction near the leading edge.

(5) The increment of the suction and injection slot size can remarkably reduce the sonic boom intensity and the drag coefficients. However, the sonic boom intensity will not decrease but will increase when the suction and injection slot size reaches a certain value. Thus, the appropriate suction and injection slot size should be chosen.

(6) The low-boom and low-drag design method is effective not only when the angle of attack is zero but also at the non-zero attack angle, and it is suitable for the supersonic aircraft within the range of small attack angle.

\section{Acknowledgments}

This work was supported by the National Natural Science Foundation of China (Grants No. 11732013) and the National Numerical Windtunnel project (NNW2019ZT3-A15).

Authors' contributions

Our group has been working on the topic for a long time. The research output comes from our joint efforts. All authors read and approved the final manuscript.

Funding

This work was supported by the National Natural Science Foundation of China (Grants No. 11732013) and the National Numerical Windtunnel project (NNW2019ZT3-A15).

Availability of data and materials

All data and materials are available upon request.

\section{Declaration}

Competing interests

The authors declare that they have no competing interests.

Received: 18 February 2021 Accepted: 20 July 2021

Published online: 01 September 2021

References

1. Feng XQ, Li ZK, Song BF (2014) Research of low boom and low drag supersonic aircraft design. Chin J Aeronaut 27(3): 531-541. https://doi.org/10.1016/j.cja.2014.04.004

2. Ma BP, Wang G, Ren J, Ye Z, Lei ZJ, Zha GC (2018) Near-field sonic-boom prediction and analysis with hybrid grid Navier-Stokes solver. J Aircr 55(5):1890-1904. https://doi.org/10.2514/1.C034659

3. Abraham TA, Hunsaker DF, Weaver-Rosen JM, Malak RJ (2020) Identifying optimal equivalent area changes to reduce sonic boom loudness. AIAA Scitech 2020 Forum, AIAA Paper 2020-0790. https://doi.org/10.2514/6.2020-0790

4. Kirz J, Rundnik R (2019) DLR TAU simulations for the second AIAA sonic boom prediction workshop. J Aircr 56(3):912927. https://doi.org/10.2514/1.C034819

5. Elmiligui A, Carter MB, Nayani SN, Cliff S, Pearl JM (2019) USM3D simulations for second sonic boom workshop. J Aircr 56(3):928-937. https://doi.org/10.2514/1.C034831

6. Derlaga JM, Park MA, Rallabhandi SK (2019) Application of exactly linearized error transport equations to sonic boom prediction workshop. J Aircr 56(3):953-961. https://doi.org/10.2514/1.C034841

7. Plotkin KJ (1989) Review of sonic boom theory. 12th AlAA Aeroacoustics Conference, AIAA Paper 1989-1105. https://doi. org/10.2514/6.1989-1105

8. Alonso JJ, Colonno MR (2012) Multidisplinary optimization with applications to sonic-boom minimization. Annu Rev Fluid Mech 44(1):505-526. https://doi.org/10.1146/annurev-fluid-120710-101133

9. Seebass R (1969) Sonic boom theory. J Aircr 6(3):177-184. https://doi.org/10.2514/3.44032

10. Kane EJ (1973) Review of current sonic boom studies. J Aircr 10(7):395-399. https://doi.org/10.2514/3.44378

11. Darden CM (1977) Sonic boom theory: its status in prediction and minimization. J Aircr 14(6):569-576. https://doi.org/1 $0.2514 / 3.58822$ 
12. Liebhardt B, Luetjens K, Gollnick V (2011) Estimation of the market potential for supersonic airliners via analysis of the global premium ticket market. 11th AIAA Aviation Technology, Integration, and Operations (ATIO) Conference, AIAA Paper 2011-6806. https://doi.org/10.2514/6.2011-6806

13. Cheung SH, Edwards TA, Lawrence SL (1992) Application of computational fluid dynamics to sonic boom near- and mid-field prediction. J Aircr 29(5):920-925. https://doi.org/10.2514/3.46263

14. Nadarajah SK, Jameson A, Alonso JJ (2002) Sonic boom reduction using an adjoint method for wing-body configurations in supersonic flow. 9th AIAA/ISSMO Symposium on Multidisciplinary Analysis and Optimization Conference, AIAA Paper 2002-5547. https://doi.org/10.2514/6.2002-5547

15. Jones LB (1961) Lower bounds for sonic bangs. J Aeronamutical Soc 65(606):433-436. https://doi.org/10.1017/s03683931 00074757

16. Carlson HW (1962) The lower bound of attainable sonic-boom overpressure and design methods of approaching this limit. NASA TN-D-1494

17. Carlson HW (1964) Influence of airplane configuration on sonic boom characteristics. J Aircr 1(2):82-86. https://doi.org/1 $0.2514 / 3.43562$

18. George AR, Seebass R (1971) Sonic boom minimization including both front and rear shocks. AIAA J 9(10):2091-2093. https://doi.org/10.2514/3.6478

19. Seebass R, George AR (1972) Sonic boom minimization. J Acoustic Soc Am 51(2):684-694. https://doi.org/10.1121/1.1 975937

20. Darden CM (1979) Sonic-boom minimization with nose-bluntness relaxation. NASA TP-1348, p .1-58

21. Ordaz I, Li W (2016) Approximation of off-body sonic-boom analysis for low-boom conceptual design. J Aircr 53(1):1419. https://doi.org/10.2514/1.C033159

22. Minelli A, Din IS, Carrier G (2014) Inverse design approach for low-boom supersonic configurations. AlAA J 52(10):21982212. https://doi.org/10.2514/1.J052834

23. Zhang YD, Huang JT, Gao ZH, Wang C, Shu B (2019) Inverse design of low boom configurations using proper orthogonal decomposition and augmented Burgers equation. Chin J Aeronaut 32(6):1380-1389. https://doi.org/10.101 6/j.cja.2019.03.017

24. Marconi F, Bowersox R, Schetz J (2003) Sonic boom alleviation using keel configurations. J Aircr 40(2):363-369. https:// doi.org/10.2514/2.3101

25. Howe DC (2005) Improved sonic boom minimization with extendable nose spike. 43rd AlAA Aerospace Sciences Meeting and Exhibit, AIAA Paper 2005-1014. https://doi.org/10.2514/6.2005-1014

26. Freund D, Simmons F, Spivey ND, Schuster L (2007) Quiet Spike ${ }^{\mathrm{TM}}$ prototype flight test results. 48th AIAA/ASME/ASCE/ AHS/ASC Structures, Structural Dynamics, and Materials Conference, AIAA Paper 2007-1778. https://doi.org/10.2514/6.2 007-1778

27. Ban N, Yamazaki W, Kusunose K (2018) Low-boom/low-drag design optimization of innovative supersonic transport configuration. J Aircr 55(3):1071-1080. https://doi.org/10.2514/1.C034171

28. Sun Y, Smith H (2019) Low-boom low-drag solutions through the evaluation of different supersonic business jet concepts. Aeronautic J 124(1271):76-95. https://doi.org/10.1017/aer.2019.131

29. Sun Y, Smith H (2019) Low-boom low-drag optimization in a multidisciplinary design analysis optimization environment. Aerosp Sci Technol 94:1-20. https://doi.org/10.1016/j.ast.2019.105387

30. Anthonv RP (2007) Spectrally accurate prediction of sonic boom signals. AlAA J 45(9):2149-2156. https://doi.org/10.2 $514 / 1.28159$

31. Cheung S, Edwards T, Lawrence S (1990) Application of CFD to sonic boom near and midfield prediction. NASA TM102867

32. Siclari MJ, Darden CM (1993) Euler code prediction of near-field to midfield sonic boom pressure signatures. J Aircr 30(6):911-917. https://doi.org/10.2514/3.46434

33. Whitham GB (1952) The flow pattern of a supersonic projectile. Commun Pure Appl Math 5(3):301-348. https://doi.org/1 0.1002/(ISSN)1097-0312

34. Rallabhandi SK (2011) Advanced sonic boom prediction using the augmented Burgers equation. J Aircr 48(4):1245-1253. https://doi.org/10.2514/1.C031248

35. Auger T, Coulouvrat F (2002) Numerical simulation of sonic boom focusing. AIAA J 40(9):1726-1734. https://doi.org/10.2 $514 / 2.1877$

36. Kanamori M, Takahashi T, Makino Y (2017) Effect of low-boom waveform on focus boom using lossy nonlinear Tricomi analysis. AIAA J 55(6):2029-2042. https://doi.org/10.2514/1.J055226

37. Xu R (2016) Numerical comparison of prediction methods for ground sonic boom evaluation on supersonic vehicle. National Conference on Aeroacoustics (in Chinese)

38. Thomas CL (1972) Extrapolation of sonic boom pressure signatures by the waveform parameter method. NASA TN D6832

39. Leatherwood JD, Sullivan BM, Shepherd KP (2002) A summary of recent NASA studies of human response to sonic booms. J Acoustic Soc Am 111(1):586-598. https://doi.org/10.1121/1.1371767

40. Zha GC, Paxton CD, Conley CA, Wells A, Carroll BF (2006) Effect of injection slot size on the performance of coflow jet airfoil. J Aircr 43(4):987-995. https://doi.org/10.2514/1.16999

41. Zha G-C, Paxton C (2004) A novel airfoil circulation augment flow control method using co-flow jet. NASA CP-2005213509, June 2005; also AIAA Paper 2004-2208

\section{Publisher's Note}

Springer Nature remains neutral with regard to jurisdictional claims in published maps and institutional affiliations. 